\title{
Disentangling Catalytic Activity at Terrace and Step Sites on Selectively Ru-Modified Well-Ordered Pt Surfaces Probed by CO Electro-oxidation
}

\author{
Manuel J. S. Farias, ${ }^{1,}$, William Cheuquepán ${ }^{2}$, Giuseppe A. Camara ${ }^{1}$, Juan M. Feliu² \\ ${ }^{1}$ Instituto de Química, Universidade Federal de Mato Grosso do Sul, C.P. 549, 79070- \\ 900, Campo Grande, Brazil
}

${ }^{2}$ Instituto de Electroquímica, Universidad de Alicante Ap. 99, E-03080, Alicante, Spain

\begin{abstract}
In heterogeneous (electro)catalysis, the overall catalytic output results from responses of surface sites with different catalytic activities, and their discrimination in terms of what specific site is responsible for a given activity is not an easy task. Here, we use the electrooxidation of $\mathrm{CO}$ as a probe reaction to access the catalytic activity of different sites on high Miller index stepped Pt surfaces with their $\{110\}$ steps selectively modified by $\mathrm{Ru}$ at different coverage. Data from in situ FTIR spectroscopy and cyclic voltammetry evidence that $\mathrm{Ru}$ deposited on $\{110\}$ steps modifies the surface in a non-trivial way, only favoring the electrocatalytic oxidation of CO over $\{111\}$ terraces. Moreover, these $\{111\}$ terraces become catalytically active throughout a large potential window. On the other hand, after the deposition of $\mathrm{Ru}$ on $\{110\}$ steps, the partial oxidation of a $\mathrm{CO}$ adlayer (by stripping voltammetry and in situ FTIR potential steps) show that those $\{110\}$ steps that remain free of $\mathrm{Ru}$ seem to be not influenced by the presence of this metal. As a result, the remaining $\mathrm{CO}$ adlayer is oxidized on these $\mathrm{Ru}$-free $\{110\}$ steps at potentials identical to those observed in steps of pure stepped Pt surfaces (in absence of Ru). Firstly, these
\end{abstract}


findings suggest that $\mathrm{CO}_{\text {ads }}$ behaves as a motionless species during its oxidation. Secondly, they evidence that the impact caused by the presence of $\mathrm{Ru}$ in the catalytic activity of $\mathrm{Pt}(\mathrm{s})-[(n-1)(111) \times(110)]$ stepped surfaces depends on the crystallographic orientation of Pt sites. These results help us to shed new light about the role of $\mathrm{Ru}$ in the mechanism of oxidation of $\mathrm{CO}$ and allow a deeper understanding regarding the $\mathrm{CO}$ tolerance in Pt-Ru catalysts.

Keywords: Electrocatalysis, Ru-modified $\mathrm{Pt}(h k l)$ surfaces, bifunctional mechanism, activity of step sites, $\mathrm{CO}$ oxidation, $\mathrm{CO}$ surface diffusion.

${ }^{*}$ Corresponding Author:

manueljsfarias@gmail.com; Phone:+55 6733453596 (M.J.S.F.). 


\section{Introduction}

The electro-oxidation of $\mathrm{CO}$ on pure Pt and Pt-based catalysts is a prototypical reaction widely studied due to its pertinence for both polymer electrolyte and direct alcohol fuel cells. ${ }^{1,2}$ In electrocatalysis, two metallic surfaces based on combinations of $\mathrm{Pt}$ and $\mathrm{Ru}$ are still recognized to be promising catalysts for both fuel cells. ${ }^{3,4}$ From an historical viewpoint, the deep impact coming from $\mathrm{Ru}$ in electrocatalysis of methanol electro-oxidation on Pt-Ru electrodes was reported in a review by Bockris and Wroblowa more than fifty years ago. ${ }^{5}$ This subject has received renewed attention over the years, but the elucidation of the synergetic effect existent in $\mathrm{Pt}-\mathrm{Ru}$ (and $\mathrm{Pt}$ in combination with other metals) to explain its catalytic enhancements, for instance, for oxidation of hydrogen poisoned by $\mathrm{CO}$, is not exactly clear. ${ }^{6}$ The understanding on the underlying mechanism in the catalytic activity enhancement of Pt by Ru for reactions involving $\mathrm{CO}$ in any step pathway might shed light on the opportunity to design efficient catalysts for fuel cells operating with $\mathrm{H}_{2}$ containing traces of $\mathrm{CO}$ as impurity, ${ }^{7}$ so that models have been developed to explain the synergism between these metals.

Methanol dissociatively adsorbs on Pt likely originating $\mathrm{HCO}_{\text {ads }}$ species, ${ }^{8,9}$ whose oxidation to $\mathrm{CO}_{2}$ requires oxygen from water molecules. Based on this proposition, Watanabe and Motoo ${ }^{10}$ rationalized the superior catalytic performance of $\mathrm{Pt}-\mathrm{Ru}$ in terms of the intrinsic $\mathrm{Ru}$ ability to promote the water oxidation step $\left(\mathrm{H}_{2} \mathrm{O} \rightleftarrows \mathrm{OH}_{\text {ads }}+\mathrm{H}^{+}+e^{-}\right)$at low potentials, something that, according to this proposition, $\mathrm{Pt}$ is not able to do. According to the so-called bifunctional mechanism at the interface of Pt-Ru each metal in surface should act as responsible for the promotion of different steps in the overall reaction. ${ }^{10-12}$ This model has been complemented by an electronic effect (ligand effect). ${ }^{13,14}$ Accordingly, Ru produces perturbations in the energy of the surface $d$-band of $\mathrm{Pt},{ }^{13,15}$ which can result in modifications on both the strength of Pt-(CO) bond and the 
activation energy of reaction, in such a way that on Pt surfaces modified by $\mathrm{Ru}, \mathrm{Pt}-(\mathrm{CO})$ might be easily oxidized to $\mathrm{CO}_{2}$ at potentials lower than those required in Pt alone. ${ }^{14}$ Besides electronic effects, it is well known that the attachment of foreign atoms to a substrate can also induce changes in the catalytic properties of the substrate, once different equilibrium positions are attained due to strains in lattice constant provoked by these foreign atoms, ${ }^{16-18}$ in which both electronic and strain effects are expected to operate simultaneously. ${ }^{19}$ The combined action of bifunctional mechanism and electronic effect has been proposed to explain the role of Pt-Ru during $\mathrm{CO}$ electro-oxidation, ${ }^{13}$ but the bifunctional mechanism is still the predominant model to explain the behavior of such systems. . $11,12,20-22$

The bifunctional mechanism requires that during $\mathrm{CO}$ electro-oxidation the limiting step reaction at low overpotentials is a bimolecular collision between neighboring $\mathrm{Pt}_{\mathrm{K}^{-}}$ (CO) and an activated $\mathrm{Ru}_{\gamma}-\left(\mathrm{H}_{2} \mathrm{O}\right)$ species at a threshold potential via a LangmuirHinshelwood mechanism, being the formation of the last species promoted on $\mathrm{Ru}$ domains. For $\mathrm{CO}$ oxidation on a Pt-Ru electrode, it means that $\mathrm{Ru}$ domains must act as centers for nucleation of oxygen-containing species, and the occurrence of the bifunctional mechanism requires $\mathrm{CO}_{\text {ads }}$ diffusion from Pt domains to active Pt sites near $\mathrm{Ru}$ sites. Specifically regarding a CO stripping experiment on Pt-Ru surfaces (in which there is no external supply of $\mathrm{CO}$ to the surface), in the potential window of CO oxidation, it would be expected that the supply of $\mathrm{CO}_{\text {ads }}$ to the "active sites" be secured via $\mathrm{CO}_{\text {ads }}$ diffusion from any $\mathrm{Pt}$ sites to those in the Ru surroundings. Conversely, multiple $\mathrm{CO}$ stripping peaks would be expected during a voltammetric stripping of CO. In this sense, in absence of anion adsorption in acid solution, the overall $\mathrm{CO}$ electro-oxidation at the perimeter of Pt and Ru domains at "lower potentials" should be formally written as: ${ }^{22-24}$

$$
\mathrm{Pt}_{\kappa}-(\mathrm{CO})+\mathrm{Ru}_{\gamma}-\left(\mathrm{H}_{2} \mathrm{O}\right) \rightarrow \mathrm{CO}_{2}+\kappa \mathrm{Pt}+\gamma \mathrm{Ru}+2 \mathrm{H}^{+}+2 e^{-}
$$


also at "lower potentials" on Ru domains, the overall reaction is: ${ }^{23}$

$$
\mathrm{Ru}_{\propto}-(\mathrm{CO})+\mathrm{Ru}_{\gamma}-\left(\mathrm{H}_{2} \mathrm{O}\right) \rightarrow \mathrm{CO}_{2}+(\propto+\gamma) \mathrm{Ru}+2 \mathrm{H}^{+}+2 e^{-}
$$

On the other hand, no matter if $\mathrm{CO}$ is adsorbed on step or terrace sites, the oxidation of $\mathrm{CO}_{\text {ads }}$ on Pt sites far from $\mathrm{Ru}_{\gamma}\left(\mathrm{H}_{2} \mathrm{O}\right)$ has been conceived to occur only at "higher" electrode potentials, ${ }^{23,24}$ which in such case would be the oxidation of CO on $\{111\}$ terraces (denoted as PtT). Under this condition, the overall reaction should be formally written as: $:^{23,24}$

$$
\mathrm{Pt}_{\mathrm{T}}-(\mathrm{CO})+\mathrm{Pt}_{\mathrm{T}}-\left(\mathrm{H}_{2} \mathrm{O}\right) \rightarrow \mathrm{CO}_{2}+2 \mathrm{Pt}_{\mathrm{T}}+2 \mathrm{H}^{+}+2 e^{-}
$$

Experiments in order to check all these hypotheses require well-structured catalysts and are still scarce in the literature. Aiming to shed some light on this issue, models in which $\mathrm{CO}_{\mathrm{ads}}$ diffuses from Pt domains to those sites at the periphery of Ru domains have been claimed, ${ }^{25}$ although such hypothesis has never been supported by any experimental evidence. On Ru-modified $\mathrm{Pt}(111)$ catalysts, whose surface is characterized by a large number of Ru nano-islands on $\{111\}$ terraces, ${ }^{26-28}$ the $\{111\}$ Pt domains free of Ru have been traditionally claimed to be little active, ${ }^{23,24}$ leaving space for a possible interpretation in terms of catalysis promoted via electronic effects induced by Ru on Pt sites, even those far from Ru domains. Moreover, by employing Ru-modified Pt(111) or Ru-modified Pt nanoparticles, besides the restrict CO mobility, the existence of well-defined zones (rich either in Pt or $\mathrm{Ru}$ ) in such electrodes has been placed at the core of the general framework to explain the origins of the peaks multiplicity in CO stripping voltammetry. ${ }^{24,25}$ Hence, multiple peaks might occur in one of the following situations: (i) slow CO diffusion from Pt domains to the perimeter of the $\mathrm{Ru}$ islands, due unfavorable binding energy ${ }^{29}$ (ii) strong adsorbed sulfate hindering $\mathrm{CO}_{\mathrm{ads}}$ mobility from $\mathrm{Pt}$ sites to the periphery of $\mathrm{Ru}$ domains ${ }^{24}$ (iii) $\mathrm{OH}_{\text {ads }}$ acting as a barrier for the diffusion of $\mathrm{CO}$ to highly active sites. ${ }^{30}$ 
Alternative interpretations concerning the catalytic enhancement of $\mathrm{Pt}-\mathrm{Ru}$ have appeared in current literature. By careful correlation between surface structure of $\mathrm{Pt}$ deposited on $\mathrm{Ru}(0001)$ crystals and its resulting catalytic activity, a potential induced surface restructuring has been pointed out to play a dominant role in the high catalytic activity of those catalysts to the oxidation of bulk $\mathrm{CO}$ at lower potentials. ${ }^{31,32}$ Moreover, it was also concluded that at low potentials $(\sim 0.6 v s . \mathrm{RHE} / \mathrm{V}), \mathrm{Ru}(0001)$ terraces are more active for $\mathrm{CO}$ oxidation than the inter-metallic boundary of RuPt, in which the traditional bifunctional mechanism apparently fails. ${ }^{32}$ In addition, Chen and Tong ${ }^{33}$ recently revised the bifunctional mechanism for methanol oxidation on PtRu electrodes. The authors concluded that the presence of CO on Pt sites in intermetallic boundaries is "irrelevant" for the catalytic enhancement of methanol oxidation at low potentials. ${ }^{33}$ According to the authors, a reaction pathway involving adsorbed formate (which decomposes to $\mathrm{CO}_{2}$ ) arises at intermetallic PtRu boundaries. ${ }^{33}$

Aiming electrocatalytic applications, the electrodeposition of metals $\left[\mathrm{M}_{(\mathrm{aq})}{ }^{z+}+\mathrm{S}_{(\mathrm{s})}\right.$ $\left.+z e^{-} \rightarrow \mathrm{M} / \mathrm{S}_{(\mathrm{s})}\right]$ is a widely studied field for the fabrication of bimetallic and multi-metallic materials resulting in different surface structures. ${ }^{34-37}$ These structures usually exhibit catalytic activities superior than the individual metals. In many cases, in situ STM (Scanning Tunneling Microscopy) studies shown that the growth of new structures (for instance, one-dimension chains and two-dimension ad-islands) on a base substrate is strongly influenced by the presence of sites with low coordination number (steps, defects, kinks and so on), on which metal deposition starts. ${ }^{38,39}$ In a previous study, by using underpotential deposition, it has been shown that it is possible to decorate only the steps [having either (110) or (100) symmetry] of Pt high Miller index surfaces with Ru, keeping (111) Pt terraces completely free. ${ }^{40-42}$ Compared to pure Pt, the oxidation of CO on these modified surfaces is deeply affected. Namely, the presence of $\mathrm{Ru}$ at Pt steps reduces 
greatly the onset potential for this reaction, but the kind of sites which have their catalytic activities affected by Ru hitherto has not been elucidated yet. Additionally, for stepped Pt surfaces with similar (111) terrace widths, it was found that the electro-oxidation of CO starts at similar potentials, regardless of whether the steps have $\{110\}$ or $\{100\}$ symmetry. ${ }^{41}$ Although the Ru deposited forms new steps on the surface, a similar onset potential oxidation indicates that the new structure ( $\mathrm{Ru}$ steps) cancels the original one (Pt steps). To the best of our knowledge, there is neither in situ nor ex situ STM topographical studies of electrochemically $\mathrm{Ru}$ decorated at Pt stepped surfaces. However, recently Carbonio et al. $^{43}$ published a study of ex situ STM under UHV conditions at room temperature for a $\operatorname{Pt}(332)$ surface on which $\mathrm{Ru}\left(\theta_{\mathrm{Ru}} \simeq 0.34 \mathrm{ML}\right)$ was exclusively attached at the rows of step sites by sputtering deposition. For this Ru coverage, it were resolved both $1 \mathrm{D}$ chain and 2D dimensional structures formed by Ru only in Pt steps, while for $\theta_{\mathrm{Ru}}$ $\simeq 0.94 \mathrm{ML}$, a mix including bilayers was observed. ${ }^{43}$ Under electrochemical conditions, selectively deposited $\mathrm{Ru}$ at steps of stepped Pt surfaces can be successful checked by cyclic voltammetry when the electrode potential is swept around the hydrogen adsorption/desorption region. ${ }^{41}$

Insights about the mechanism of catalytic influence of Ru in Pt-Ru catalysts can be accessed by using $\operatorname{Pt}(111)$ vicinal surfaces selectively modified by $\mathrm{Ru}$, especially if the study starts from experiments whose Pt crystal surfaces were selectively modified by Ru at increasing coverage degrees. This experimental strategy allows assessing the impact of $\mathrm{Ru}$ in the catalytic activity of different Pt active sites (terraces and steps, free of $\mathrm{Ru}$ ). However, as stated before, questions about dynamic/mobility of $\mathrm{CO}$ on surfaces as well as the assignment of specific sites (and/or domains) which had its catalytic activity affected by $\mathrm{Ru}$ (in steps) remains open. This contribution attempts to address these questions. In order to do that, we selectively decorated $\{110\}$ steps of $\operatorname{Pt}(111)$ vicinal 
surfaces by electrochemical deposition of Ru at different coverage. In situ FTIR (Fourier Transform Infrared) spectroscopy and cyclic voltammetry at well-defined electrodes were employed to follow the electro-oxidation of a full $\mathrm{CO}$ adlayer and with this species previously adsorbed only on step sites.

\section{Experimental Section}

In this study, we have used stepped Pt crystals, namely $\operatorname{Pt}(554)$ and $\operatorname{Pt}(332)$, with geometric areas ranging between $\sim 3$ and $\sim 5 \mathrm{~mm}^{2}$, as working electrodes. The Pt crystals were prepared following the procedure described by Clavilier et al.. ${ }^{44}$ These stepped surfaces contain $n$ atom-wide (111) terraces periodically broken by monoatomic steps with $\{110\}$ symmetry. According with Lang-Joyner-Somorjai ${ }^{45}$ (LJS model), those $\operatorname{Pt}(111)$ vicinal surfaces can be denoted as $\operatorname{Pt}(\mathrm{s})-[(n-1)(111) \times(110)]$. In addition, this series of stepped surfaces also might be presented as $\operatorname{Pt}(\mathrm{s})-[n(111) \times(111)]$, but for the purpose of describing electrochemical behavior coming from the $(111) \times(111)$ junction that is a step, the former notation is more representative ${ }^{46}$ since it is assigned as (110) steps. According with LJS model (and using the first notation), individually the two stepped surfaces above can be represented as:

$$
\begin{aligned}
& \operatorname{Pt}(\mathrm{s})-[9(111) \times(110)] \equiv \operatorname{Pt}(554) \\
& \operatorname{Pt}(\mathrm{s})-[5(111) \times(110)] \equiv \operatorname{Pt}(332)
\end{aligned}
$$

The Pt crystals were flame annealed in a butane/air flame and cooled down in a controlled $\mathrm{H}_{2} / \mathrm{Ar}$ atmosphere. Subsequently, the surface of each crystal was protected by a droplet of deoxygenated $\left(\mathrm{H}_{2} / \mathrm{Ar}\right)$ water, and then it was transferred to the electrochemical cell. A platinized Pt wire was used as a counter electrode and the reference electrode was a reversible hydrogen electrode (RHE), being all the potentials presented in this scale. All experiments were carried out in $0.1 \mathrm{M} \mathrm{HClO}$ (Merck 
suprapur) solution in ultrapure water (Milli-Q 18.2 M $\Omega \mathrm{cm}$ ). To degasing the electrolyte solution, we used Ar (Alpha Gaz ${ }^{\mathrm{TM}}$, N50). For the stripping experiments, CO (Alpha $\mathrm{Gaz}^{\mathrm{TM}}$, N47) was injected directly through solution for $5 \mathrm{~min}$ (unless otherwise stated) with the electrode potential kept at $0.100 \mathrm{~V}$. Next, non-adsorbed CO was replaced by Ar bubbling into the solution for $20 \mathrm{~min}$ (unless otherwise stated).

To selectively decorate the Pt stepped surfaces with $\mathrm{Ru}$, we employ a solution of $\mathrm{RuCl}_{3} \cdot x \mathrm{H}_{2} \mathrm{O}$ (Merck) whose concentration was of about $\sim 1.4 \times 10^{-5} \mathrm{M}$ prepared in ultrapure water. The electrochemical deposition of $\mathrm{Ru}$ was carried out during electrode potential swept in the range of $0.060 \mathrm{~V}-0.300 \mathrm{~V}$ at $0.05 \mathrm{~V} \mathrm{~s}^{-1}$. The fraction of $\{110\}$ steps covered by $\mathrm{Ru}$ (denoted as $\theta_{\mathrm{Ru}}^{\text {Step }}$ ) on stepped Pt surfaces was calculated as:

$$
\theta_{\mathrm{Ru}}^{\mathrm{Step}} \simeq \frac{Q_{\mathrm{H}}^{\mathrm{S}, 0}-Q_{\mathrm{H}}^{\mathrm{S}, \mathrm{Ru}}}{Q_{\mathrm{H}}^{\mathrm{S}, 0}}
$$

where $Q_{\mathrm{H}}^{\mathrm{S}, 0}$ and $Q_{\mathrm{H}}^{\mathrm{S}, \mathrm{Ru}}$ refer to the hydrogen desorption charge densities from steps in $\mathrm{Pt}$ clean and after the deposition of Ru, respectively.

To remove deposited $\mathrm{Ru}$ from $\mathrm{Pt}$ surface, the Pt crystal was wet in concentrated nitric acid, and then it was heated in a butane/air flame until the nitric acid "exploded" on the surface. The procedure was repeated about ten times. Then, the Pt crystal was flame annealed and cooled down as described before, and cyclic voltammograms were collected to confirm the complete removal of $\mathrm{Ru}$. Further, to confirm $\mathrm{Ru}$ removal a new $\mathrm{CO}$ stripping voltammetry was recorded and compared with an identical experiment before any $\mathrm{Ru}$ deposition. In all cases, the absence of extra catalytic activity indicated that $\mathrm{Ru}$ was completely removed from the Pt surface. Afterwards, further experiments with other $\mathrm{Ru}$ coverage were performed.

For in situ FTIR experiments, we employed a Nicolet (Model 8700) spectrometer, equipped with a MTC (Mercury-Cadmium-Telluride) detector and cooled down with 
liquid $\mathrm{N}_{2}$. We used a spectro-electrochemical cell with a thin layer configuration ${ }^{47}$ formed by pressing the single crystal against $\mathrm{CaF}_{2}$ prismatic $\left(60^{\circ}\right)$ window. Spectra were acquired by the co-addition of 200 averaged scans with a resolution of $8 \mathrm{~cm}^{-1}$ (the acquisition time of each spectrum was about $90 \mathrm{~s}$ ), from 0.060 until $0.800 \mathrm{~V}$, at intervals of $50 \mathrm{mV}$. The resulting spectra are presented in absorbance units, $A=-\log \left[\left(R_{0}-R_{i}\right) / R_{0}\right]$ $v s . v / \mathrm{cm}^{-1}$, in which the term $R_{0}$ is a single-beam reflectance reference spectrum either at $0.800 \mathrm{~V}$ or $0.060 \mathrm{~V}$ (specified in section 3.5), while $R_{i}$ is a single beam reflectance spectrum at a sample potential. According with the notation for $A$, positive bands (pointing up) in spectra mean that species were formed into the thin layer, while negative ones (pointing down) refer to species that were consumed or diffused out from the thin layer. All experiments were made by employing a $p$-polarized radiation which allows to detect IR active species both at the electrode surface and dissolved into the thin layer, ${ }^{47}$ according to the surface selection rule..$^{48,49}$

Electrode potentials were controlled by using a waveform generator (EG\&G PARC 175) together with a potentiostat (Amel 551) and a digital recorder (eDAC ED 401). All the experiments were carried out at room temperature $\left(25^{\circ} \mathrm{C}\right)$.

\section{Results}

\subsection{Electrochemical Characterization of Unmodified and Ru-Modified Pt Crystals}

Figure 1 compares cyclic voltammograms of $\operatorname{Pt}(554)$ and $\operatorname{Pt}(332)$ crystals before and after their selective modifications by $\mathrm{Ru}$ electrochemical deposition. This figure includes hard sphere models for these stepped surfaces. In Figures 1A and 1C, the features of the cyclic voltammograms imply that both surfaces were of high-quality oriented and wet in contact with lightly clean solutions. The reversible feature at $\sim 0.128 \mathrm{~V}$ is due to 
hydrogen desorption/adsorption at $\{110\}$ step sites. Further details about the description of Pt single crystals in electrochemical solution can be consulted in the work of Climent et al..$^{50}$

Panels B and D in Figure 1 show the evolution of the voltammetric profile after Ru deposition on these crystals. In order to achieve Ru deposition, cyclic voltammograms were first recorded in the supporting electrolyte solution at $0.05 \mathrm{~V} \mathrm{~s}^{-1}$ from $0.060 \mathrm{~V}$ to $0.300 \mathrm{~V}$ in the meniscus configuration. Next, an aliquot of ruthenium chloride solution was added into the electrochemical cell $\left(\sim 1.4 \times 10^{-5} \mathrm{M}\right)$ while the potential was swept at $0.05 \mathrm{~V} \mathrm{~s}^{-1}$ from 0.060 up to $0.300 \mathrm{~V}$. After reached a certain degree of suppression in hydrogen desorption/adsorption currents by Ru deposition, a single cyclic voltammogram was recorded from $0.060 \mathrm{~V}$ up to $0.800 \mathrm{~V}$ at the same scan rate to check the complete voltammetric profile (including the double layer region). As can be seen in Figures 1B and $1 \mathrm{D}$, hydrogen desorption/adsorption at $\{110\}$ steps is the feature affected by $\mathrm{Ru}$ deposition. Based on this finding, it is reasonable to affirm that Ru deposits preferentially at the steps, leaving $\{111\}$ terraces completely free, as previously reported either by electrochemical deposition ${ }^{41,43}$ or sputtering deposition under UHV environments. ${ }^{43}$ For $\operatorname{Pt}(554)$, the original charge density (in absence of $\mathrm{Ru}$, denoted as $\theta_{\mathrm{Ru}}^{\text {Step }}=0.00$, black line) under the feature peak at $\sim 0.128 \mathrm{~V}$ was of about $28.9 \mu \mathrm{C} \mathrm{cm}^{-2}$. As Ru deposits on Pt steps, the magnitude of this feature gradually decreases. In red the curve, the remaining charge density was of $\sim 18 \mu \mathrm{C} \mathrm{cm}^{-2}$, which allows us to estimate the fraction of steps covered by $\mathrm{Ru}$ as $\theta_{\mathrm{Ru}}^{\text {Step }} \simeq 0.38$. After a further Ru deposition (blue line), the remaining charge density decreases to $\sim 10 \mu \mathrm{C} \mathrm{cm}^{-2}$, and the fraction of Pt steps covered by $\mathrm{Ru}$ was $\theta_{\mathrm{Ru}}^{\text {Step }} \simeq 0.65$. In last case, the profile of electric double layer (from $\sim 0.35 \mathrm{~V}$ up to $\sim 0.65 \mathrm{~V}$ ) appears considerably disrupted, suggesting that adsorbed $\mathrm{Ru}$ undergoes oxygen adsorptive reactions. 
For $\mathrm{Pt}(332)$, the charge density under the peak centered at $\sim 0.128 \mathrm{~V}$ was of $49.9 \mu \mathrm{C}$ $\mathrm{cm}^{-2}$ in absence of $\mathrm{Ru}\left(\theta_{\mathrm{Ru}}^{\text {Step }}=0.00-\right.$ black line $)$. After $\mathrm{Ru}$ deposition, this charge decreases to $\sim 39.1 \mu \mathrm{C} \mathrm{cm}^{-2}$ and $32.3 \mu \mathrm{C} \mathrm{cm}^{-2}$ resulting in $\theta_{\mathrm{Ru}}^{\text {Step }}$ of about 0.22 and 0.35 , respectively. On both surfaces, the general trend is the deposition of Ru preferentially at Pt steps. Only after these sites being fully covered, the occupancy of terraces clearly starts (See Figure SI 1).

\subsection{Catalytic Activity towards the Electro-Oxidation of $\mathrm{CO}$ without Assignment of Active Sites}

Figure 2 displays cyclic voltammetries for the $\mathrm{CO}$ oxidation on unmodified and $\mathrm{Ru}-$ modified stepped Pt surfaces correspondent to that shown in Figure 1. In these experiments, the electrode potential was kept at $0.100 \mathrm{~V}$, and a saturated $\mathrm{CO}$ adlayer was formed as described in section 2. After Ar purging, the $\mathrm{CO}$ adlayer was oxidized at once by sweeping the electrode potential from $0.060 \mathrm{~V}$ to $0.800 \mathrm{~V}$.

For pure $\mathrm{Pt}(554)$ (black lines in Figures $2 \mathrm{~A}$ or 2B), $\mathrm{CO}$ oxidation abruptly starts at $\sim 0.72 \mathrm{~V}$ and a single oxidation peak appears at $\sim 0.76 \mathrm{~V}$. The exact potential in which $\mathrm{CO}$ oxidation starts will be further examined by in situ FTIR, which is a better technique for this purpose. In Figure 2 the $\mathrm{CO}$ pre-oxidation was prevented by controlling the time for

replacing the solution $\mathrm{CO}$ by $\mathrm{Ar}$, as discussed in a previous publication. ${ }^{51}$ For $\theta_{\mathrm{Ru}}^{\text {Step }}$ of 0.38 and 0.65 in $\operatorname{Pt}(554)$ (red and olive lines, respectively), CO oxidation abruptly starts at $\sim 0.55 \mathrm{~V}$ and ends at $\sim 0.76 \mathrm{~V}$. This wide potential window $(\Delta E \simeq 210 \mathrm{mV})$ in which $\mathrm{CO}$ oxidizes contrasts with the narrow $\Delta E(\sim 60 \mathrm{mV}$, from $\sim 0.72$ to $\sim 0.78 \mathrm{~V}$ - black line $)$ observed for $\operatorname{Pt}(554)$ in absence of $\mathrm{Ru}$. Furthermore, the large $\Delta E$ for $\mathrm{CO}$ oxidation wave for $\theta_{\mathrm{Ru}}^{\text {Step }}$ of 0.38 and 0.65 in $\operatorname{Pt}(554)$ consists of three oxidation peaks, assigned as 1, 2, 
and 3, respectively: Peak 1 appears at $\sim 0.57 \mathrm{~V}$, followed by peak 2 at $\sim 0.62 \mathrm{~V}$ and peak 3 at $\sim 0.71 \mathrm{~V}$. The magnitude of the peaks depends on the Ru coverage at Pt steps, so that, when $\theta_{\mathrm{Ru}}^{\text {Step }} \simeq 1.0$ (blue line in Figures $2 \mathrm{~A}$ or $2 \mathrm{~B}$ ), peak 1 becomes dominant. It is worth noting that in case of $\theta_{\mathrm{Ru}}^{\mathrm{Step}} \simeq 1.0$, the potential window for CO oxidation is also very narrow, but a small shoulder persists at $\sim 0.7 \mathrm{~V}$, which can be attributed to the predominance of currents from the formation of Ru oxide/hydroxide. Only for qualitative purposes, we have also estimated the global charge (i.e., the uncorrected charge that includes those currents arising from events taking place to restore the double layer region) of the stripping voltammetry. For Ru coverage of 0.38 and 0.65 , the uncorrected charges of CO stripping (integrated from $0.300 \mathrm{~V}$ to $0.800 \mathrm{~V}$ ) were $\sim 443 \pm 3 \mu \mathrm{C} \mathrm{cm}^{-2}$; while for $\theta_{\mathrm{Ru}}^{\text {Step }} \simeq 1.0$, the global charge was $\sim 532 \pm 15 \mu \mathrm{C} \mathrm{cm}^{-2}$. In the last case (blue line), the charge of $\mathrm{CO}$ oxidation becomes less accurate because there are strong disturbances in the substrate voltammetry (Figure SI 1), coming from the contribution of oxide/hydroxide (the broad shoulder at $\sim 0.70 \mathrm{~V}$ ) that makes the estimation of the oxidation charge very imprecise.

In case of $\mathrm{Pt}(332)$, displayed in Figure $2 \mathrm{C}$ or 2D (black line), $\mathrm{CO}$ oxidation abruptly starts after $\sim 0.70 \mathrm{~V}$ and presents a single peak starting at $\sim 0.73 \mathrm{~V}$ that ends at $\sim 0.76 \mathrm{~V}$, meaning a $\Delta E \simeq 60 \mathrm{mV}$. However, when the surface is modified by $\mathrm{Ru}$, the $\mathrm{CO}$ oxidation starts at $\sim 0.50 \mathrm{~V}$ and persists until $\sim 0.75 \mathrm{~V}$, regardless of Ru coverage. For the lower Ru coverage on Pt steps (coverage 0.22 and 0.35$), \Delta E \simeq 250 \mathrm{mV}$. Similar to $\mathrm{Pt}(554)$, multiple $\mathrm{CO}$ peaks also appear in $\mathrm{Ru}$-modified $\mathrm{Pt}(332)$ surfaces. The $\mathrm{CO}$ oxidation wave also consists of multiple oxidation peaks and peak 1 also becomes more prominent as $\mathrm{Ru}$ coverage increased to $\theta_{\mathrm{Ru}}^{\text {Step }} \simeq 1$. 0 . For $\theta_{\mathrm{Ru}}^{\text {Step }} 0.22$ and 0.35 the uncorrected charge of CO stripping $(0.300 \mathrm{~V}-0.800 \mathrm{~V})$ was of $431 \pm 6 \mu \mathrm{C} \mathrm{cm}^{-2}$, while for $\theta_{\mathrm{Ru}}^{\text {Step }} \simeq 1.0$, it was of 
$\sim 585 \mu \mathrm{C} \mathrm{cm}^{-2}$. The reasons for the high charge density and higher uncertainty of $\mathrm{CO}$ oxidation charge at high Ru coverage are the same already discussed for $\operatorname{Pt}(554)$.

Figure 3 compares $\mathrm{CO}$ stripping on both $\mathrm{Pt}(554)$ and $\mathrm{Pt}(332)$ having similar $\mathrm{Ru}$ coverage on Pt steps. On Ru-modified Pt(332), the CO oxidation starts abruptly about 50 $\mathrm{mV}$ earlier than on Ru-modified $\mathrm{Pt}(554)$. The shift in the onset potential for $\mathrm{CO}$ oxidation might be attributed to the width of the $\{111\}$ terraces. This trend was confirmed by us using a Ru-modified Pt(331) (Figure SI 2), on which the potential of CO oxidation was lower than on $\operatorname{Pt}(554)$ and on $\operatorname{Pt}(332)$. Finally, on both surfaces $\mathrm{CO}$ oxidation persists at high potentials $(\sim 0.75 \mathrm{~V})$.

\subsection{Catalytic Activity Assignment of Terraces and Steps by Voltammetry During the Stripping of a Partial CO Adlayer}

Figure 4 shows partial oxidation of a saturated $\mathrm{CO}$ adlayer on Ru-modified stepped Pt surfaces. Here, the formation of $\mathrm{CO}$ adlayer and elimination of non-adsorbed $\mathrm{CO}$ were done as above. However, the upper potentials were controlled to secure that the $\mathrm{CO}$ adlayer was oxidized portion by portion, instead of at once. Thus, starting with a complete

CO adlayer on $\operatorname{Pt}(554)$ modified by $\theta_{\mathrm{Ru}}^{\mathrm{Step}} \simeq 0.38$ (Figure 4A), in the first cycle (red line), the electrode potential was swept up to $0.620 \mathrm{~V}$, and then it was stepped back to $0.100 \mathrm{~V}$, before the re-start of the sweep. At the end of each partial stripping excursion, the electrode potential was always stepped back to $0.100 \mathrm{~V}$. The currents of the second cycle (blue line) show that those sites available for hydrogen desorption after the first cycle were exclusively $\{111\}$ terraces. Subsequent cycles continue releasing only $\{111\}$ terrace sites, and only at the $5^{\text {th }}$ cycle (olive line), Pt step sites become free. Then the CO electrooxidation peak appears at $\sim 0.72 \mathrm{~V}$. The oxidation peak at $\sim 0.72 \mathrm{~V}$ is assigned to the 
oxidation of $\mathrm{CO}_{\mathrm{ads}}$ on the step sites which remained free from $\mathrm{Ru}$ (i.e., Ru has never been adsorbed on these particular sites). This figure also displays a voltammetric sweep for the complete CO adlayer oxidation in a single sweep (black line). As can be seen in Figure 4A, contributions of peaks 1 and 2 (as designated in Figure 2) are exclusively due to the $\mathrm{CO}$ oxidation over $\{111\}$ terraces, while peak 3 is due to the $\mathrm{CO}$ oxidation on both terraces and steps. It is important to clarify that by cyclic voltammetry we cannot know if the contribution from $\mathrm{CO}$ oxidation on $\mathrm{Ru}$ sites develops in processes 1,2 or 3 . This issue will be discussed after in situ FTIR experiments (and will be addressed in the next section).

The observations done for Ru-modified Pt(554) in Figure 4A can be extrapolated to the $\mathrm{CO}$ electro-oxidation on Ru-modified $\mathrm{Pt}(332)$ shown in Figure $4 \mathrm{~B}$, in which $\theta_{\mathrm{Ru}}^{\text {Step }}$ $\simeq 0.35$. That means that $\sim 65 \%$ of $\{110\} \mathrm{Pt}$ steps were free for $\mathrm{CO}$ adsorption without being previously modified by Ru adsorption. As in Figure 4A, at the end of $\mathrm{CO}$ adlayer oxidation, the peak of $\mathrm{CO}$ oxidation at steps grows only at $\sim 0.72 \mathrm{~V}$ (olive line).

\subsection{Intrinsic Catalytic Activity at (110) Pt Steps Modified and non-Modified by Ru}

First, in this work, we will define intrinsic catalytic activity at $\{110\}$ Pt steps as the catalytic activity toward $\mathrm{CO}$ oxidation when $\{111\}$ terraces were completely free of $\mathrm{CO}$. In this case, it is possible to perform comparisons between potentials required for $\mathrm{CO}$ oxidation on pure Pt steps (before Ru adsorption) and those Pt step sites that remain free after the surface being modified by $\mathrm{Ru}$ (hereafter designed as "remaining Pt steps"). Thus, in order to record the experiments shown in Figure 5, a $\mathrm{CO}$ adlayer was formed on each surface (Ru-modified or not) and then it was voltammetrically stripped from the terraces until $\mathrm{CO}_{\text {ads }}$ remained only in Pt step sites. Figure 5 compares $\mathrm{CO}$ oxidation on Pt steps of 
Pt(554) surfaces at two conditions: (1) pure Pt steps, i.e., Pt steps in stepped surfaces that have not being modified by $\mathrm{Ru}$; (2) remaining Pt steps. As can be seen in Figure 5, the potentials in which $\mathrm{CO}$ oxidation starts at Pt steps (no matter if it they had or not $\mathrm{Ru}$ as neighbor) are essentially identical $(\sim 0.66 \mathrm{~V})$. The oxidation develops a peak at $\sim 0.72 \mathrm{~V}$ and ends at $\sim 0.76 \mathrm{~V}$ for all cases.

From Figure 5 we can see that for pure Pt steps (black line), there are sites free for hydrogen desorption even before $\mathrm{CO}$ being oxidized (peak at $\sim 0.13 \mathrm{~V}$ ), which means that although the CO coverage at pure $\{110\}$ Pt steps is not complete, the corresponding CO oxidation charge during the stripping was higher (charge over the peak at $\sim 0.72 \mathrm{~V}$ ). Such apparent discrepancy suggests that the $\mathrm{CO}_{\mathrm{ads}}$ which persisted until $0.72 \mathrm{~V}$ was that adsorbed in the remaining Pt steps, and not the one adsorbed on Ru sites. Such behavior is expected since "pure" $\mathrm{Ru}$ is highly catalytic towards $\mathrm{CO}$ electro-oxidation. ${ }^{14}$

\subsection{Catalytic Activity Assignment of Terraces and Steps by in situ FTIR Spectroscopy}

$\mathrm{CO}$ electro-oxidation on pure and Ru-modified stepped Pt surfaces was studied by in situ FTIR spectroscopy. Figure 6 shows spectra for $\mathrm{CO}$ on pure $\operatorname{Pt}(332)$. To record this experiment, the electrode potential was kept at $0.100 \mathrm{~V}$ and $\mathrm{CO}$ was bubbled into the solution for $3 \mathrm{~min}$. Next, non-adsorbed $\mathrm{CO}$ was replaced by $\mathrm{Ar}$ gas (12 min of purge). Spectra in Figure 6B show wavenumbers ranging from 1750 to $2230 \mathrm{~cm}^{-1}$ for a complete $\mathrm{CO}$ adlayer. Spectra exhibit two potential-dependent $\mathrm{CO}$ bands. ${ }^{52}$ For instance, the spectrum at $0.150 \mathrm{~V}$ (red line) shows a band at $2064 \mathrm{~cm}^{-1}$ attributed to the stretching $v(\mathrm{C}$ O) mode of linearly bonded $\mathrm{CO}$ (denoted as $\mathrm{CO}^{L}$ ) mainly on $\{111\}$ terraces; other band appears at $\sim 1828 \mathrm{~cm}^{-1}$ attributed to the stretching $\mathrm{v}(\mathrm{C}-\mathrm{O})$ mode of bridge-bonded $\mathrm{CO}$ (denoted as $\mathrm{CO}^{B}$ ) on $\{111\}$ terraces. Both $\mathrm{CO}$ bands survive until about $0.60 \mathrm{~V}$ (blue 
line), after which they disappear due to the oxidation of the $\mathrm{CO}$ adlayer. Figure 6A shows the stretch vibration of $\mathrm{CO}_{2}$ band $\left(2343 \mathrm{~cm}^{-1}\right)$ for various potentials for the same experiment shown in Figure 6B. We note that the formation of $\mathrm{CO}_{2}$ starts at $\sim 0.50 \mathrm{~V}$.

Figure 6C displays spectra for $\mathrm{CO}$ adsorbed only on $\{110\}$ Pt steps of a $\mathrm{Pt}(332)$ surface. In this experiment, the $\mathrm{CO}$ adlayer was formed and non-adsorbed $\mathrm{CO}$ was eliminated from solution as described before. Then, the $\mathrm{CO}$ adsorbed on $\{111\} \mathrm{Pt}$ terraces was voltammetrically eliminated by controlling the upper potential limit, in order to maintain the population of adsorbed CO on Pt steps intact. Spectra in Figure 6C exhibit a single potential-dependent band, which is attributed to $\mathrm{CO}^{L}$ on $\{110\} \mathrm{Pt}$ steps. For instance, at $0.150 \mathrm{~V}$ (red line) in Figure 6C, the band appears in $2024 \mathrm{~cm}^{-1}$, i.e., it appears red shifted by about $40 \mathrm{~cm}^{-1}$ in comparison to the $\mathrm{CO}^{L}$ band at full coverage shown in Figure 6B. In Figure 6B, the band due to $\mathrm{CO}$ at $\mathrm{Pt}$ steps was fully invisible due to dipoledipole coupling effect, in which the phenomenon of intensity transfer occurs to higher frequency at the expenses of lower one. ${ }^{53,54}$ Also, the $\mathrm{CO}^{B}$ band is absent in Figure $6 \mathrm{C}$, confirming that $\{110\} \mathrm{Pt}$ steps do not adsorb $\mathrm{CO}^{B}$, as previously shown. ${ }^{55}$ Figure $6 \mathrm{~B}$ also shows that the potential-dependent frequency for $\mathrm{CO}^{L}$ is not linear in all the potential range. Namely, after $0.50 \mathrm{~V}$, the $\mathrm{CO}^{L}$ frequency decreases and at $0.60 \mathrm{~V}$ it becomes identical to the band-frequency for $\mathrm{CO}^{L}$ at Pt steps (Figure 6C, same potential). These spectroscopic findings strongly support the hypothesis that the CO on Pt step sites only oxidizes after all CO molecules on Pt terraces were fully oxidized.

From Figure $6 \mathrm{~B}$, the plot of $\mathrm{d} v(\mathrm{C}-\mathrm{O}){ }^{i} / \mathrm{d} E$ (Stark tunning effect) from $0.060 \mathrm{~V}$ up to $0.450 \mathrm{~V}$ (a potential range in which $\mathrm{CO}$ does not oxidize to $\mathrm{CO}_{2}$ ) is of about $32 \mathrm{~cm}^{-1} \mathrm{~V}^{-1}$ for $\mathrm{CO}^{L}$, in good agreement with previous results, ${ }^{56}$ while for $\mathrm{CO}^{B}, \mathrm{~d} v(\mathrm{C}-\mathrm{O}){ }^{B} / \mathrm{d} E \simeq 43 \mathrm{~cm}^{-}$ ${ }^{1} \mathrm{~V}^{-1}$. For CO on $\{110\}$ Pt steps (Figure $6 \mathrm{C}$ ), $\mathrm{d} v(\mathrm{C}-\mathrm{O}){ }^{L} / \mathrm{d} E \simeq 51 \mathrm{~cm}^{-1} \mathrm{~V}^{-1}$. High $\mathrm{d} v(\mathrm{C}-\mathrm{O}) / \mathrm{d} E$ 
for $\mathrm{CO}$ on Pt steps has been reported, ${ }^{57,58}$ but the origin of this behavior is not fully understood yet.

Figures 7 and 8 show spectra collected during the electro-oxidation of a complete CO adlayer on a $\mathrm{Pt}(332)$ surface with their $\{110\}$ Pt steps partially modified by $\mathrm{Ru}$ at two different coverage. In both cases, a CO adlayer was formed and the subsequent protocol was similar to that already described. In Figure $7 \mathrm{~B},\left(\theta_{\mathrm{Ru}}^{\text {Step }} \simeq 0.58\right)$, spectra show that $\mathrm{CO}^{L}$ band frequency has two ranges of potential-dependence, which is similar to the behavior observed in Figure $6 \mathrm{~B}$ for the same potentials. Figure $7 \mathrm{~A}$ shows the $\mathrm{CO}_{2}$ band as a function of the potential. In this case, on $\mathrm{Ru}$-modified $\mathrm{Pt}(332)$, the $\mathrm{CO}_{2}$ formation starts at $\sim 0.40 \mathrm{~V}$, which is about $0.1 \mathrm{~V}$ lower than on pure $\operatorname{Pt}(332)$ shown in Figure 6A. The band for $\mathrm{CO}^{B}$ in Figure 7B is very small. Screening of the IR band of bridge bonded $\mathrm{CO}$ has been reported for epitaxial $\mathrm{Cu}$ on $\mathrm{Pt}(111)$ under ultra-high vacuum environment. ${ }^{59} \mathrm{It}$ is worth noting in Figure $7 \mathrm{~B}$ that at the end of $\mathrm{CO}$ adlayer oxidation, the $\mathrm{CO}$ frequency presents a red shift that is characteristic of $\mathrm{CO}$ in $\mathrm{Pt}$ steps, resulting in a $\mathrm{CO}$ band frequency similar to that shown in Figure $6 \mathrm{C}$ for the same potential. This is spectroscopic evidence that the $\mathrm{CO}$ adsorbed at remaining Pt steps is oxidized only after all $\mathrm{CO}$ on $\{111\}$ Pt terraces is converted into $\mathrm{CO}_{2}$, in perfect agreement with data shown in Figure 5. From Figure 7B, the slope of $\mathrm{d} v(\mathrm{C}-\mathrm{O}) / \mathrm{d} E$ is $\sim 33 \mathrm{~cm}^{-1} \mathrm{~V}^{-1}$, which is very similar to that measured for $\mathrm{CO}$ on pure $\operatorname{Pt}(332)$ shown in Figure 6.

For higher Ru coverage (Figure $8 \mathrm{~B}$ ), i.e., when $\theta_{\mathrm{Ru}}^{\text {Step }}=1.0$ plus a significant portion of Ru on $\{111\}$ terraces $\left(\theta_{\mathrm{Ru}}^{\mathrm{Terrace}} \simeq 0.35\right)$, spectra show three bands attributed to adsorbed CO. For instance, at $0.150 \mathrm{~V}$, the $\mathrm{CO}^{L}$ band on $\{111\} \mathrm{Pt}$ terraces appears at $2051 \mathrm{~cm}^{-1}$ (downshifted). Meanwhile a new wide band appears at $1984 \mathrm{~cm}^{-1}\left(\Delta v \simeq-85 \mathrm{~cm}^{-1}\right)$, which is characteristic of the vibrational signature of $\mathrm{CO}^{L}$ on Ru sites, ${ }^{14,60}$ finally, another band 
appears at $\sim 1833 \mathrm{~cm}^{-1}$ which is attributed to $\mathrm{CO}^{B}$ on Pt sites. ${ }^{14}$ The potential at which $\mathrm{CO}_{2}$ formation starts is $\sim 0.30 \mathrm{~V}$ (Figure $8 \mathrm{~A}$ ), that is $\sim 0.1 \mathrm{~V}$ lower in comparison to the experiment depicted in Figure 7A.

Only when the total $\mathrm{Ru}$ coverage is high, the band at $\sim 1984 \mathrm{~cm}^{-1}$ emerges. One reason why this band is not observed in spectra in Figure 7B (low Ru coverage), is likely because bands for both $\mathrm{CO}^{L}$ on $\mathrm{Pt}$ and $\mathrm{Ru}$ domains are strongly vibrationally coupled. As $\mathrm{CO}^{L}$ on Pt has higher singleton frequency, it predominates ${ }^{53,54}$ at the expenses of $\mathrm{CO}^{L}$ on $\mathrm{Ru}$. However, when $\mathrm{Ru}$ starts to occupy terraces, the population of $\mathrm{CO}$ on $\mathrm{Ru}$ sites increases enormously, and the corresponding $\mathrm{CO}^{L}$ band on $\mathrm{Ru}$ rises. Worth of notice is that the band intensities for $\mathrm{CO}^{L}$ decrease simultaneously at both $\mathrm{Ru}$ and $\mathrm{Pt}$ sites (Figure 9). At the end of $\mathrm{CO}$ oxidation (spectra at $0.400 \mathrm{~V}$ and $0.450 \mathrm{~V}$ in Figure 8), bands at $\sim 2036 \mathrm{~cm}^{-1}$ and $\sim 2023-2017 \mathrm{~cm}^{-1}$ emerge. These bands differ from those obtained either on Pt or on Ru sites. Friedrich et al. ${ }^{61}$ by using FTIR and Lu et al. ${ }^{62}$ by using SFG (Sum Frequency Generation) have reported simultaneous decreases in bands of $\mathrm{CO}$ both on $\mathrm{Pt}$ and $\mathrm{Ru}$ sites. For $\theta_{\mathrm{Ru}}=1$ on a $\mathrm{Pt}(111)$ in acid media at 0.2 vs. $\mathrm{RHE} / \mathrm{V},{ }^{14}$ a single $\mathrm{CO}$ band appeared at $2005 \mathrm{~cm}^{-1}$ related to $\mathrm{CO}^{L}$. But when total $\theta_{\mathrm{Ru}}=0.75$, the authors observed two bands at $2050 \mathrm{~cm}^{-1}$ and $2012 \mathrm{~cm}^{-1}$, related to $\mathrm{CO}^{L}$ on $\mathrm{Pt}$ and $\mathrm{Ru}$, respectively ${ }^{14}$. Experiments by In Lin et al. ${ }^{14}$ for $\operatorname{Pt}(111)$ with $\theta_{\mathrm{Ru}} \simeq 0.2$ also show two $\mathrm{CO}^{L}$ bands, assigned to the adsorption of $\mathrm{CO}$ on $\mathrm{Pt}$ and $\mathrm{Ru}$ sites. However, for $\theta_{\mathrm{Ru}} \simeq 0.2$ data of theses authors do not shown, for instance at $0.10 \mathrm{vs}$. RHE/V, any changes in frequency for $\mathrm{CO}^{L}$ at Pt sites compared to the pure $\mathrm{Pt}(111)$ crystal. In our case, a similar trend can be seen in Figure 7B when compared to Figure 6B.

From data shown in Figure $8 \mathrm{~B}$, the plot of $\mathrm{d} v(\mathrm{C}-\mathrm{O})^{i} / \mathrm{d} E$, from $0.060 \mathrm{~V}$ up to $0.300 \mathrm{~V}$, is $\sim 34 \mathrm{~cm}^{-1} \mathrm{~V}^{-1}$ for $\mathrm{CO}^{L}$ on Pt sites and $\sim 38 \mathrm{~cm}^{-1} \mathrm{~V}^{-1}$ for $\mathrm{CO}^{\mathrm{L}}$ on $\mathrm{Ru}$ ones. In these spectra, $\mathrm{CO}^{B}$ appears ill-defined, so that $\mathrm{d} v(\mathrm{C}-\mathrm{O}){ }^{B} / \mathrm{d} E$ is very imprecise. For a Ru-modified $\mathrm{Pt}(111)$, 
Friedrich et al..$^{61}$ found a $\mathrm{d} v(\mathrm{C}-\mathrm{O})\left(\mathrm{d} E \simeq 48 \mathrm{~cm}^{-1} \mathrm{~V}^{-1}\right.$ for $\mathrm{CO}$ on Ru sites. In other studies involving Ru-modified $\operatorname{Pt}(111)$ surfaces $\left(\theta_{\mathrm{Ru}} \simeq 0.75\right)$, it was found a $\mathrm{d} v(\mathrm{C}-\mathrm{O}){ }^{L} / \mathrm{d} E$ of about $39 \mathrm{~cm}^{-1} \mathrm{~V}^{-1}$ and $43 \mathrm{~cm}^{-1} \mathrm{~V}^{-1}$ for $\mathrm{CO}$ on Pt and Ru domains, ${ }^{14}$ respectively.

Figure 10 compares spectra for $\mathrm{CO}_{\text {ads }}$ on different catalysts at two electrode potentials. These spectra were extracted from Figures 6, 7 and 8. In Figure 10A spectra were taken at $0.200 \mathrm{~V}$, i.e., a potential where $\mathrm{CO}_{\text {ads }}$ is electrochemically stable on this electrode. In Figure 10A (red and black lines), we can see that the $\mathrm{CO}^{L}$ bands on $\{110\}$ Pt steps and on Ru sites are separated by $\sim 40 \mathrm{~cm}^{-1}$. At $0.500 \mathrm{~V}$ (Figure 10B), the band

intensity for $\mathrm{CO}$ on $\mathrm{Ru}$-modified surfaces $\left(\theta_{\mathrm{Ru}}^{\mathrm{Step}} \simeq 0.58\right)$ is very small (blue line), because this electrode is more active than pure Pt at this potential. Another highlight from Figure $10 \mathrm{~B}$ is the fact that band frequencies (and intensities) in black and blue lines are virtually identical. From this comparison, it is reasonable to assume that the band at $2046 \mathrm{~cm}^{-1}$ (blue line - Figure 10B) is due to the linearly bonded CO at the remaining Pt steps. In case of full $\mathrm{CO}$ adlayer (dark cyan line), the $\mathrm{CO}$ band remains almost intact, due to the low catalytic activity of pure Pt at $0.500 \mathrm{~V}$.

\section{General Discussion}

\subsection{Influence of $R u$ Decoration}

The deposition of $\mathrm{Ru}$ from a diluted $\mathrm{Ru}(\mathrm{III})$ solution $\left(\sim 1.4 \times 10^{-5} \mathrm{M}-\right.$ low rate of mass transport) on the family of $\operatorname{Pt}(\mathrm{s})-[(n-1)(111) \times(110)]$ stepped surfaces preferentially starts on Pt steps, as can be inferred from the pattern evolution of cyclic voltammetry in hydrogen region (Figures 1B and 1D). This finding is in perfect agreement with data reported earlier. ${ }^{41,43}$ Moreover, Ru deposition on the terraces starts only when steps are completely occupied. Similar to the UHV environments, ${ }^{43}$ in view of such preferential 
$\mathrm{Ru}$ deposition, it is reasonable to assume that also under electrochemical conditions, $\mathrm{Ru}$ at low coverages on Pt steps forms mainly monoatomic rows along the original crystalline rows of Pt steps. This selective Ru modification of the Pt steps allowed us to successfully study the impact of Ru in the catalytic activity of neighbour $\{111\}$ terraces and other sites uncovered by $\mathrm{Ru}$. In this respect, it has been evidenced that the most active sites for $\mathrm{CO}$ electro-oxidation lie over the terraces in pure $\operatorname{Pt}(\mathrm{s})-[(n-1)(111) \times(110)]$ stepped surfaces (Figure 6), irrespective of the nature of electrolyte solution. ${ }^{51,55} \mathrm{We}$ found similar trends here, even when the steps are partially modified by $\mathrm{Ru}$ (Figures 2, 4 and 7). That is, $\mathrm{Ru}$ on the $\{110\}$ Pt steps deeply modifies the catalytic activity of the $\{111\}$ Pt terraces, even those away from Ru. However, its influence in the catalytic activity of the $\{110\}$ remaining uncovered Pt steps is weaker (Figures 4, 5 and 7). Before addressing this subject, it is convenient to discuss the current understanding about the $\mathrm{CO}$ electrooxidation on pure Pt single crystals.

For pure $\operatorname{Pt}(\mathrm{s})-[(n-1)(111) \times(110)]$ stepped surfaces,${ }^{51,55}$ the high catalytic activity toward CO electro-oxidation observed over the $\{111\}$ Pt terraces has been partially linked to the lower binding of $\mathrm{CO}$ on the electronically perturbed terraces provoked by dipole associated to the steps. By employing Pt stepped surfaces, it is well known from surface science studies ${ }^{63-66}$ that the adsorption energy of CO at low coordinated sites is larger than on terrace domains. It is likely that such strongly bound $\mathrm{CO}$ at the low coordinated sites, at least to some extent, is related to the lower catalytic activity observed for $\mathrm{CO}$ (electro)oxidation on step/kink sites. Terraces and steps behave as energetically very different places. According to the Smoluchowski effect, ${ }^{67,68}$ the upper part of the steps exhibits a decreased $d$-electron density, while at the bottom of the steps occurs the accumulation of charge density, i.e., at the corrugated surfaces, the dipole moment associated to the steps results in a higher density of unoccupied $d$-states at the top of these 
sites. Hence, it is likely that a gradient of energy occurs over $\{111\}$ terraces, resulting in catalytic consequences, as observed for $\mathrm{CO}$ electro-oxidation over these surface domains, ${ }^{55}$ in which the low part of the step, i.e., the concave domains of $\{111\}$ orientation, might be highest catalytic active sites for $\mathrm{CO}$ oxidation. When $\operatorname{Pt}(\mathrm{s})-[(n-$ 1)(111) $\times(110)$ ] stepped surfaces had their steps partially modified by $\mathrm{Ru}$, data in Figures 2 and 4 show that there is a wide potential window along which $\{111\}$ Pt terraces become more catalytically active for the electro-oxidation of $\mathrm{CO}$. In this case, there is a clear reduction in the onset potential of $\mathrm{CO}$ oxidation, but only on the $\{111\}$ Pt terraces. On other hand, by using two series of $\operatorname{Pt}(\mathrm{s})-[(n-1)(111) \times(110)]$ and $\operatorname{Pt}(\mathrm{s})-[(n)(111) \times(100)]$ stepped surfaces, Chen et al. ${ }^{69}$ found that the irreversible blockage of their steps either by Te or Bi hinders the catalytic activity of the modified surfaces. Namely, the poisoning effect observed by Chen et al. ${ }^{69}$ on $\{111\}$ Pt terraces (the onset potential for CO electrooxidation shifts to more positive potentials) suggests that when Te or Bi fully block $\{110\}$ Pt steps, the modified stepped surface presents catalytic activity like a $\operatorname{Pt}(111)$ single crystal. ${ }^{69}$ In this occasion, those authors assumed that steps/kinks were the most active sites. On the other hand, the modification of steps in Pt stepped surfaces either by adatoms as $\mathrm{Ru}, \mathrm{Mo}$, or $\mathrm{Sn}$ boosts the catalytic activity toward $\mathrm{CO}$ electro-oxidation. ${ }^{40}$ These results suggest different and non-trivial mechanism played by ad-atoms in modifications of the catalytic activity on $\{111\}$ Pt terraces in these electrodes. Unfortunately, the structure of these ad-atoms on Pt steps of Pt stepped surfaces is not studied yet.

Here, $\{111\}$ Pt terraces become catalytically more active once their steps are decorated by $\mathrm{Ru}$ simultaneously to the "variation" of site activity when the surface becomes more heterogeneous. That is, the reaction begins to take place into a wide overpotential window $(\Delta \eta)$. For instance, for $\mathrm{Pt}(554)$ in Figures 2-3, Ru deposition on $\mathrm{Pt}$ steps induces a deep change in potential window $(\Delta E)$ in which $\{111\}$ Pt terraces present 
high catalytic activity. $\Delta E$ increases from $60 \mathrm{mV}$ before Ru deposition (Figure 2A, black line) to $210 \mathrm{mV}$ after Ru deposition (Figure 2A, olive and red lines). Such enlargement in the reaction potential window along which $\{111\}$ Pt terraces are active to convert CO into $\mathrm{CO}_{2}$ corresponds to a change in the standard free Gibbs energy of reaction from $~ 11.6$ $\mathrm{kJ} \mathrm{mol}^{-1}$ to $40.5 \mathrm{~kJ} \mathrm{~mol}^{-1}$, respectively. At the same time, multiple $\mathrm{CO}$ oxidation peaks (whose origin is not fully understood yet) are observed within that potential range of $\sim 210$ $m V$. Furthermore, if Ru at Pt steps affects the catalytic activity over $\{111\}$ Pt terraces, data in Figure 2 allow us suppose that such effect might depend on the amount of Ru at those steps. Correspondingly, Figure 2 shows that $\mathrm{CO}$ oxidation current densities in peak 1 increase as the Ru coverage (on Pt steps) grows. When Pt steps become fully covered by $\mathrm{Ru}$, the oxidation of $\mathrm{CO}$ occurs essentially in peak 1 (which turns into a narrow single peak, $\Delta E \simeq 70 \mathrm{mV}$, Figure 2, blue line). Such behavior suggests that the catalytic activity grows uniform at long of $\{111\}$ Pt terraces as the steps are increasingly covered by $\mathrm{Ru}$. Thus, such changing (and tailoring) in the catalytic activity over $\{111\}$ Pt terraces induced by distant rows of Ru on Pt steps strongly suggests that a long-range effect could act over $\{111\}$ Pt terraces free of $\mathrm{Ru}$ (provoked by either the strain character and/or the ligand effect). Also, Figure 3 (and Figure SI 2) evidence that the extent by which Ru (on steps) affects the catalytic activity of $\{111\}$ Pt terraces depends on the width of these terraces. Summarizing, the change in catalytic reactivity over $\{111\}$ Pt terraces seems to be due to an additional change in the magnitude in dipole moment associated to the steps after $\mathrm{Ru}$ deposition on Pt steps (PtRu $\left.\mathrm{u}_{\text {step }}\right)$ combined with the $\{111\}$ Pt terrace width. PtRustep seems to modify the catalytic features of $\{111\}$ Pt terraces even when they are away from rows of Ru-modified steps. The observations discussed before make clear that the catalytic enhancement of PtRu systems cannot be fully explained based on the traditional bifunctional mechanism, at least for CO stripping, as will be deeper discussed next. 


\subsection{Mechanistic Considerations}

As already highlighted in the introduction, during the stripping of $\mathrm{CO}$, the assumption of the traditional bifunctional mechanism implies in a high $\mathrm{CO}$ mobility on the surface from any Pt site to the periphery of Ru islands, since this model assumes the most active sites are located in the PtRu interface. However, experiments depicted in Figures 4 and 7 evidence that $\{111\}$ Pt terraces are the first sites to be released during the partial oxidation of a CO adlayer, while $\{110\}$ Pt steps are the last ones. This releasing "hierarchy" evidences that both Ru on Pt steps (forming a PtRustep) and remaining Pt steps (i.e., those Pt steps free of $\mathrm{Ru}$ ) are less catalytically active for the CO oxidation than $\{111\}$ Pt terraces electronically perturbed by $\mathrm{PtRu}_{\text {step }}$ (see data in Figures 4, 5 and 7). This result allows to evaluate separately the catalytic activity for $\mathrm{CO}$ oxidation in $\{111\}$ terraces and $\{110\}$ steps of $\mathrm{Pt}$ (those remaining free of $\mathrm{Ru}$ ) on $\mathrm{Ru}$-modified surfaces. Concerning the catalytic activity of PtRu interfaces to the $\mathrm{CO}$ oxidation, by using well-characterized $\mathrm{Pt}$ deposited on $\mathrm{Ru}(0001)$ crystals, Engstfeld et al. ${ }^{31,32}$ proposed that the mere presence of $\mathrm{Pt}$ in the immediate surroundings of $\mathrm{Ru}$ cannot explain the expressive catalytic enhancement for $\mathrm{CO}$ bulk oxidation at low potentials. These authors suggested that for $\mathrm{Pt}$ deposited on $\mathrm{Ru}(0001)$ surfaces, the most active sites likely lie on $\{0001\} \mathrm{Ru}$ terraces rather than at the RuPt interface. Our data shows that for higher Ru coverage (Ru also on Pt terraces), $\mathrm{CO}$ on Ru sites as well as $\mathrm{CO}$ on $\{111\}$ Pt terraces are oxidized concurrently (Figure 9). Our data neither rule out nor corroborate the hypothesis that PtRu interfaces are the most catalytic ones, but they convincingly show that PtRusteps and remaining $\mathrm{Pt}_{\text {steps }}$ are little catalytic active for $\mathrm{CO}$ oxidation (Figures 5 and 7), so that, $\mathrm{Ru}$ on Pt steps only impacts in the catalytic activity of $\{111\}$ terraces. Therefore, the influence of $\mathrm{Ru}$ in the catalytic role in Pt sites seems to depend on the crystallographic orientation of Pt sites in 
$\operatorname{Pt}(\mathrm{s})-[(n-1)(111) \times(110)]$ stepped surfaces. From catalytic viewpoint, according to the Sabatier principle, ${ }^{70,71}$ for an optimum catalysis, the binding forces between the catalyst substrate and the reactants (intermediate of reactions) should be intermediate, i.e., to achieve high catalytic activity, it should be neither too weak to promote its activation nor too strong to avoid poisoning by them (in order to allow the desorption of products). Based on this principle, for pure Pt stepped surfaces, if water molecules preferentially dissociate in Pt steps unoccupied by $\mathrm{CO}$, it is reasonable to assume that this principle is fewer applicable for the pair $\mathrm{Pt}_{\kappa}$, step-CO and $\mathrm{Pt}_{\gamma}$, step- $\left(\mathrm{H}_{2} \mathrm{O}\right)_{\text {activated }}$ at lower potentials, since the formation of $\mathrm{CO}_{2}$ requires higher over-potentials to take place on these sites (blue line, Figures 6B). Similarly, in case of Ru modified Pt, it seems to be not applicable also for the pair $\mathrm{Pt}_{\kappa, \text { step }}-\mathrm{CO}$ and $\mathrm{PtRu} \mathrm{u}_{\text {step }}-\left(\mathrm{H}_{2} \mathrm{O}\right)_{\text {activated }}$ (olive and blue line, 7B). However, it seems to be better satisfied for the reaction between $\mathrm{Pt}_{\gamma}$, terrace- $\mathrm{CO}$ and $\mathrm{Pt}_{v}$, terrace-

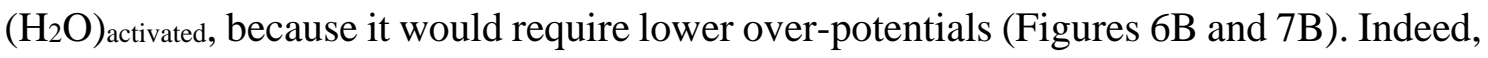
from solid/gas interface studies, ${ }^{72-74}$ it is well known that water adsorption and its dissociation preferentially occur in the upper parts of step edges compared to closepacked domains. In this respect, once the adsorbates strongly adsorb at the steps, this could at least partially explain the higher over-potentials required for the reaction $\mathrm{Pt}_{\kappa}$, step$\mathrm{CO}+\mathrm{Pt}_{\text {v, step }}-\left(\mathrm{H}_{2} \mathrm{O}\right) \rightarrow \mathrm{CO}_{2}+(\kappa+v) \mathrm{Pt}_{\text {step }}+2 \mathrm{H}^{+}+2 e^{-}$compared with those needed to promote the same reaction at the $\{111\}$ terraces of Pt stepped surfaces, being these latter modified or not by $\mathrm{Ru}$. Therefore, from data in Figures 4, 5 and 7 it is unlikely that a $\mathrm{PtRu}_{\text {step }}-\left(\mathrm{H}_{2} \mathrm{O}\right)_{\text {activated }}$ and a remaining $\mathrm{Pt}_{\kappa}$, step $(\mathrm{CO})$ satisfy the Sabatier principle for a Langmuir-Hinshelwood mechanism. Moreover, similarly to the pure $\operatorname{Pt}(\mathrm{s})-[(n-$ 1)(111) $\times(110)$ ] stepped surfaces previously reported, ${ }^{51}$ data in Figure 4 evidence that after partial oxidation of a CO adlayer, on a Ru partially modified Pt step, the sites released in the first voltammetric cycles apparently were not reoccupied by the remaining $\mathrm{CO}$ 
molecules on surface. This finding means that those molecules behave like motionless species during its oxidation, at least in the time scale of our experiments. Therefore, the sub-adlayer of $\mathrm{CO}_{\text {ads }}$ seems to behave strictly as a catalytic poison. The apparent absence of $\mathrm{CO}$ mobility during its oxidation has a deep implication in the classic bifunctional mean-field mechanism, i.e., the bifunctional mechanism fails to explain the features observed during $\mathrm{CO}$ stripping experiments on the catalysts used in this work.

In a previous work, the apparent $\mathrm{CO}$ immobility on $\mathrm{Ru}$ modified $\mathrm{Pt}(111)$ has been attributed to the strong adsorption energy of sulfate/bisulfate. ${ }^{24}$ However, we found the same apparent immobility during the oxidation of $\mathrm{CO}$ on Pt stepped surfaces in perchloric acid, whose anions are recognized by not being specifically adsorbed ${ }^{75}$ or weakly adsorbed on $\{111\}$ Pt facets. ${ }^{76}$ This finding points out that the apparent immobility of CO during its oxidation cannot be explained on the basis of a strong competing adsorption of anions ${ }^{24}$ or assuming $\mathrm{OH}_{\text {ads }}$ as a barrier for $\mathrm{CO}_{\text {ads }}$ diffusion. ${ }^{30}$ Regarding a possible electronic effect from Ru to the Pt sites, Baltruschat et al. ${ }^{36}$ proposed that the enthalpy of adsorption in the neighborhood of $\mathrm{Ru}$ is increased, and this might have implications to supply $\mathrm{CO}_{\text {ads }}$ via diffusion from any sites to the neighboring of $\mathrm{Ru}$ sites, which has been proposed to be unfavorable by DFT calculation by Koper et al.. ${ }^{29}$ About this topic, in view of both phenomena, i.e., the surface sites hierarchy for $\mathrm{CO}$ and because $\mathrm{CO}_{\mathrm{ads}}$ apparently behaves as a motionless species during its oxidation, we think that data of Figures 4 and 7 are coherent with the existence of a gradient of energy over $\{111\} \mathrm{Pt}$ terraces of Pt stepped surfaces. The remaining question is why oxygen-containing species reach "motionless" CO molecules anywhere on the $\{111\}$ Pt terraces. On this matter, Davies et al. ${ }^{24}$ proposed a spillover of activated oxygen containing species from $\mathrm{Ru}$ sites to $\mathrm{CO}_{\text {ads }}$ at any $\mathrm{Pt}$ sites, instead of water activation on those disturbed $\mathrm{Pt}$ sites far from $\mathrm{Ru}$ domains. Additionally, they proposed that this spillover process is kinetically limiting, 
which could explain the second peak during the voltammetric oxidation of $\mathrm{CO}$ at high potentials. Evidently, this proposition implies that the adsorption/desorption paths of oxygen containing species at Pt sites are in a state of non-equilibrium, what was later considered unlikely (on p.356 of ${ }^{77}$ ). One possibility is that oxygen containing species are activated around $\mathrm{CO}_{\mathrm{ads}}$ islands on electronically perturbed $\mathrm{Pt}$ domains, as we have recently assumed for the oxidation of $\mathrm{CO}$ on pure Pt stepped surfaces. ${ }^{51}$

\section{Conclusions}

Based on a detailed study of the CO electro-oxidation as an archetypical surface probe reaction, we unravel a number of catalytic properties underlying in Ru-modified well-ordered Pt surfaces:

i. $\quad$ On $\mathrm{Ru}_{\text {step }} / \mathrm{Pt}(\mathrm{s})-[(n-1)(111) \times(110)]$, the catalytic activity for adsorbed $\mathrm{CO}$ oxidation can be decoupled on that of terraces and steps. Ru at $\{110\} \mathrm{Pt}$ steps activates the reaction pathway only over the $\{111\}$ terraces, and no change was detected in the catalytic activity of $\mathrm{Pt}$ steps free of $\mathrm{Ru}$. Therefore, this means that the change in the catalytic activity of Pt sites by Ru at steps depends on the crystallographic orientation of Pt sites. Moreover, because that decoupled process of site releasing, such hierarchy allows an evaluation of the catalytic activity on terrace sites separately from that of the Pt step sites free of $\mathrm{Ru}$.

ii. At both pure $\mathrm{Pt}$ stepped surfaces and $\mathrm{Ru}$ steps $/ \mathrm{Pt}(h k l)$, $\mathrm{CO}$ behaves as a motionless species during its oxidation, which implies that the bifunctional mean-field mechanism is unable to explain the catalytic enhancement in $\mathrm{CO}$ stripping reaction on these $\mathrm{Ru}_{\text {steps }} / \mathrm{Pt}(h k l)$ surfaces. Electronic/strain effects seem more plausible to 
explain the changes in the catalytic activity observed for (111) Pt terraces of stepped surfaces after Ru deposition on their steps.

iii. On pure Pt stepped surfaces, its catalytic activity toward CO oxidation also occurs decoupled on terraces and steps sites.

\section{Associated Content}

\section{Supporting Information}

Additional experimental data concerning on purely electrochemical results (cyclic voltammetries for blank and CO stripping) are presented (PDF).

Acknowledgements: M.J.S. Farias acknowledges financial support from the CNPq (Brazil), grants No. 200390/2011-2 and 313402/2013-2. G.A. Camara acknowledges financial assistance from CNPq (grants \# 305494/2012-0, 309176/2015-8 and 405695/2013-6) and FUNDECT (grant \# 23/200.583/2012). J.M. Feliu thanks to the MINECO (Spain) project No. CTQ2013-44083-P. 


\section{References}

(1) Koper, M. T. M. Surf. Sci. 2004, 548, 1-3.

(2) Iwasita, T.; Ciapina, E. G. In Handbook of Fuel Cells, $1^{\text {st }}$ Ed.; Wielstich, W.; Gastieger, H. A. Eds. John Wiley \& Sons, Ltd, Vol. 5, 2009, p.224.

(3) Petrii, O. J. Solid State Electrochem. 2008, 12, 609-642.

(4) Kakati, N.; Maiti, J.; Lee, S. H.; Jee, S. H.; Viswanathan, B.; Yoon, Y. S. Chem. Rev. 2014, 114, 12397-12429.

(5) Bockris, J. O. M.; Wroblowa, H. J. Electroanal. Chem. (1959) 1964, 7, $428-451$.

(6) Lopes, P.; Freitas, K.; Ticianelli, E. Electrocatalysis 2010, 1, 200-212.

(7) Bagotsky, V. S. In Fundamentals of Electrochemistry; John Wiley \& Sons, Inc., 2005; pp 521-555.

(8) Petry, O. A.; Podlovchenko, B. I.; Frumkin, A. N.; Lal, H. J. Electroanal. Chem. 1965, 10, 253-269.

(9) Bagotzky, V. S.; Vassiliev, Y. B. Electrochim. Acta 1966, 11, 1439-1461.

(10) Watanabe, M.; Motoo, S. J. Electroanal. Chem. 1975, 60, 267-273.

(11) Yajima, T.; Wakabayashi, N.; Uchida, H.; Watanabe, M. Chem. Commun. 2003, 828-829.

(12) Gasteiger, H. A.; Markovic, N.; Ross Jr, P. N.; Cairns, E. J. J. Phys. Chem. 1994, 98, 617-625.

(13) Liu, P.; Nørskov, J. K. Fuel Cells 2001, 1, 192-201.

(14) Lin, W. F.; Zei, M. S.; Eiswirth, M.; Ertl, G.; Iwasita, T.; Vielstich, W. J. Phys. Chem. B 1999, 103, 6968-6977.

(15) Dimakis, N.; Iddir, H.; Díaz-Morales, R. R.; Lia, R.; Bunker, G.; Chung, E. H.; Smotkin, E. S. J. Phys. Chem. B 2005, 109, 1839-1848.

(16) Kitchin, J. R.; Nørskov, J. K.; Barteau, M. A.; Chen, J. G. Phys. Rev. Lett. 2004, 93, 156801-156801-156801-156804.

(17) Mavrikakis, M.; Hammer, B.; Nørskov, J. K. Phys. Rev. Lett. 1998, 81, 2819-2822.

(18) Pinheiro, A. L. N.; Zei, M. S.; Ertl, G. Phys. Chem. Chem. Phys. 2005, 7, 1300-1309.

(19) Mueller, J. E.; Krtil, P.; Kibler, L. A.; Jacob, T. Phys. Chem. Chem. Phys. 2014, 16, 15029-15042.

(20) Zhuang, L.; Jin, J.; Abruña, H. D. J. Am. Chem. Soc. 2007, 129, 1103311035.

(21) Mickelson, L. L.; Friesen, C. J. Am. Chem. Soc. 2009, 131, 14879-14884.

(22) Rau, M. S.; Gennero de Chialvo, M. R.; Chialvo, A. C. J. Power Sources 2012, 216, 464-470.

(23) Lu, G. Q.; Waszczuk, P.; Wieckowski, A. J. Electroanal. Chem. 2002, $532,49-55$.

(24) Davies, J. C.; Hayden, B. E.; Pegg, D. J.; Rendall, M. E. Surf. Sci. 2002, 496, 110-120.

(25) Maillard, F.; Lu, G. Q.; Wieckowski, A.; Stimming, U. J. Phys. Chem. B 2005, 109, 16230-16243.

(26) Herrero, E.; Feliu, J. M.; Wieckowski, A. Langmuir 1999, 15, 4944-4948.

(27) Crown, A.; Johnston, C.; Wieckowski, A. Surf. Sci. 2002, 506, L268-L274.

(28) Friedrich, K. A.; Geyzers, K. P.; Dickinson, A. J.; Stimming, U. J. Electroanal. Chem. 2002, 524-525, 261-272.

(29) Koper, M. T. M.; Lebedeva, N. P.; Hermse, C. G. M. Faraday Discuss. 2002, 121, 301-311. 
(30) Wang, H.; Abruña, H. D. J. Phys. Chem. Lett. 2015, 6, 1899-1906.

(31) Engstfeld, A. K.; Brimaud, S.; Behm, R. J. Angew. Chem. Int. Ed. 2014, 53, 12936-12940.

(32) Engstfeld, A. K.; Klein, J.; Brimaud, S.; Behm, R. J. Surf. Sci. 2015, 631, 248-257.

(33) Chen, D.-J.; Tong, Y. J. Angew. Chem. Int. Ed. 2015, 54, 9394-9398.

(34) Camara, G. A.; De Lima, R. B.; Iwasita, T. J. Electroanal. Chem. 2005, $585,128-131$.

(35) Kibler, L. A.; El-Aziz, A. M.; Hoyer, R.; Kolb, D. M. Angew. Chem. Int. Ed. 2005, 44, 2080-2084.

(36) Baltruschat, H.; Ernst, S.; Bogolowski, N. In Catalysis in Electrochemistry, ${ }^{\text {st }}$ Ed. Santos, E.; Schmickler, W., Eds. John Wiley \& Sons, Inc., 2011; pp 297-337.

(37) Mello, G. A. B.; Farias, M. J. S.; Janete Giz, M.; Camara, G. A. Electrochem. Commun. 2014, 48, 160-163.

(38) Nichols, R. J.; Kolb, D. M.; Behm, R. J. J. Electroanal. Chem. 1991, 313, 109-119.

(39) Batina, N.; Will, T.; Kolb, D. M. Faraday Discuss. 1992, 94, 93-106.

(40) Massong, H.; Wang, H.; Samjeské, G.; Baltruschat, H. Electrochim. Acta 2000, 46, 701-707.

(41) Samjeské, G.; Xiao, X. Y.; Baltruschat, H. Langmuir 2002, 18, 4659-4666.

(42) Mostafa, E.; Abd-El-Latif, A.-E.-A. A.; Baltruschat, H. ChemPhysChem 2014, 15, 2029-2043.

(43) Carbonio, E. A.; Prieto, M. J.; Siervo, A. d.; Landers, R. J. Phys. Chem. C 2014, 118, 28679-28688.

(44) Clavilier, J.; Armand, D.; Sun, S. G.; Petit, M. J. Electroanal. Chem. 1986, 205, 267-277.

(45) Lang, B.; Joyner, R. W.; Somorjai, G. A. Surf. Sci. 1972, 30, 440-453.

(46) Clavilier, J.; El Achi, K.; Rodes, A. Chem. Phys. 1990, 141, 1-14.

(47) Iwasita, T.; Nart, F. C. Prog. Surf. Sci. 1997, 55, 271-340.

(48) Greenler, R. G. J. Chem. Phys. 1966, 44, 310-315.

(49) Hansen, W. N. J. Opt. Soc. Am. 1968, 58, 380-388.

(50) Climent, V.; García-Araez, N.; Herrero, E.; Feliu, J. Russ. J. Electrochem. 2006, 42, 1145-1160.

(51) Farias, M. J. S.; Camara, G. A.; Feliu, J. M. J. Phys. Chem. C 2015, 119, 20272-20282.

(52) Villegas, I.; Weaver, M. J. J. Chem. Phys. 1994, 101, 1648-1660.

(53) Persson, B. N. J.; Ryberg, R. Phys. Rev. B 1981, 24, 6954-6970.

(54) Severson, M. W.; Stuhlmann, C.; Villegas, I.; Weaver, M. J. J. Chem. Phys. 1995, 103, 9832-9843.

(55) Farias, M. J. S.; Herrero, E.; Feliu, J. M. J. Phys. Chem. C 2013, 117, 29032913.

(56) Farias, M. J. S.; Busó-Rogero, C.; Gisbert, R.; Herrero, E.; Feliu, J. M. J. Phys. Chem. C 2014, 118, 1925-1934.

(57) Kim, C. S.; Korzeniewski, C.; Tornquist, W. J. J. Chem. Phys. 1994, 100, 628-630.

(58) Kim, C. S.; Korzeniewski, C. Anal. Chem. 1997, 69, 2349-2353.

(59) Rodriguez, J. A.; Truong, C. M.; Goodman, D. W. J. Chem. Phys. 1992, 96, 7814-7825. 
(60) Lin, W. F.; Christensen, P. A.; Hamnett, A.; Zei, M. S.; Ertl, G. J. Phys. Chem. B 2000, 104, 6642-6652.

(61) Friedrich, K. A.; Geyzers, K. P.; Linke, U.; Stimming, U.; Stumper, J. J. Electroanal. Chem. 1996, 402, 123-128.

(62) Lu, G. Q.; White, J. O.; Wieckowski, A. Surf. Sci. 2004, 564, 131-140.

(63) Lin, T. H.; Somorjai, G. A. Surf. Sci. 1981, 107, 573-585.

(64) Tränkenschuh, B.; Papp, C.; Fuhrmann, T.; Denecke, R.; Steinrück, H. P. Surf. Sci. 2007, 601, 1108-1117.

(65) Tränkenschuh, B.; Fritsche, N.; Fuhrmann, T.; Papp, C.; Zhu, J. F.; Denecke, R.; Steinrück, H. P. J. Chem. Phys. 2006, 124, 074712.

(66) Vattuone, L.; Savio, L.; Rocca, M. Surf. Sci. Rep. 2008, 63, 101-168.

(67) Smoluchowski, R. Phys. Rev. 1941, 60, 661-674.

(68) Park, J. Y.; Sacha, G. M.; Enachescu, M.; Ogletree, D. F.; Ribeiro, R. A.; Canfield, P. C.; Jenks, C. J.; Thiel, P. A.; Sáenz, J. J.; Salmeron, M. Phys. Rev. Lett. 2005, 95, 136802.

(69) Chen, Q. S.; Berna, A.; Climent, V.; Sun, S. G.; Feliu, J. M. Phys. Chem. Chem. Phys. 2010, 12, 11407-11416.

(70) Nørskov, J. K.; Bligaard, T.; Hvolbæk, B.; Abild-Pedersen, F.; Chorkendorff, I.; Christensen, C. H. Chem. Soc. Rev. 2008, 37, 2163-2171.

(71) Medford, A. J.; Vojvodic, A.; Hummelshøj, J. S.; Voss, J.; Abild-Pedersen, F.; Studt, F.; Bligaard, T.; Nilsson, A.; Nørskov, J. K. J. Catal. 2015, 328, 36-42.

706.

(72) Morgenstern, M.; Michely, T.; Comsa, G. Phys. Rev. Lett. 1996, 77, 703-

(73) Picolin, A.; Busse, C.; Redinger, A.; Morgenstern, M.; Michely, T. J. Phys. Chem. C 2009, 113, 691-697.

(74) Henderson, M. A. Surf. Sci. Rep. 2002, 46, 1-308.

(75) Berná, A.; Climent, V.; Feliu, J. M. Electrochem. Commun. 2007, 9, 27892794.

(76) Attard, G. A.; Brew, A.; Hunter, K.; Sharman, J.; Wright, E. Phys. Chem. Chem. Phys. 2014, 16, 13689-13698.

(77) General Discussion. Faraday Discuss. 2002, 121, 331-364. 


\section{Figures}

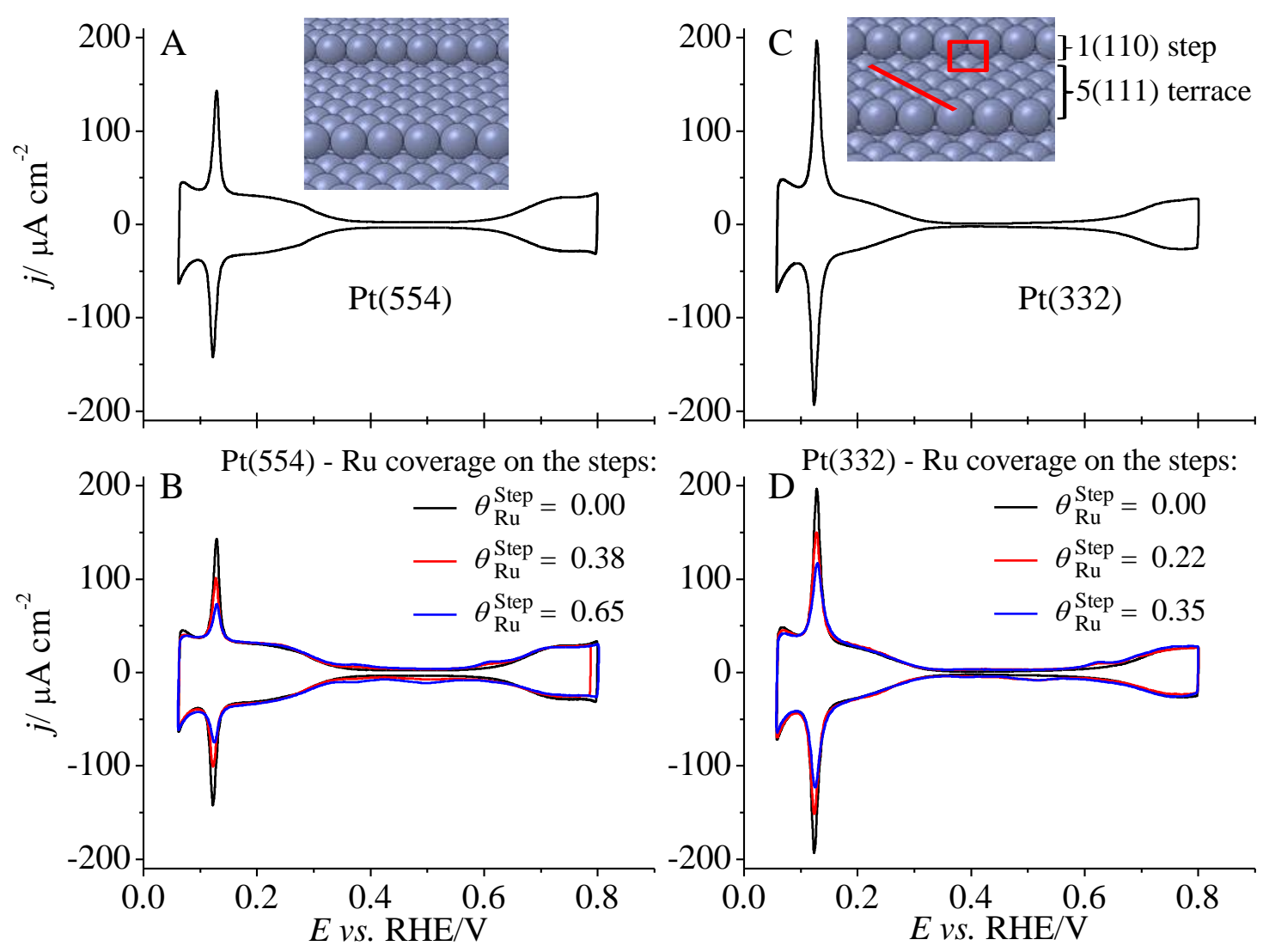

Fig. 1. Cyclic voltammetries of two stepped Pt electrodes before (A and C) and after (B and $\mathrm{D}$ ) selective modifications of their steps by $\mathrm{Ru}$. Data recorded at $0.05 \mathrm{~V} \mathrm{~s}^{-1}$ in $0.1 \mathrm{M}$ $\mathrm{HClO}_{4}$. Data includes hard sphere models of the stepped surfaces. 

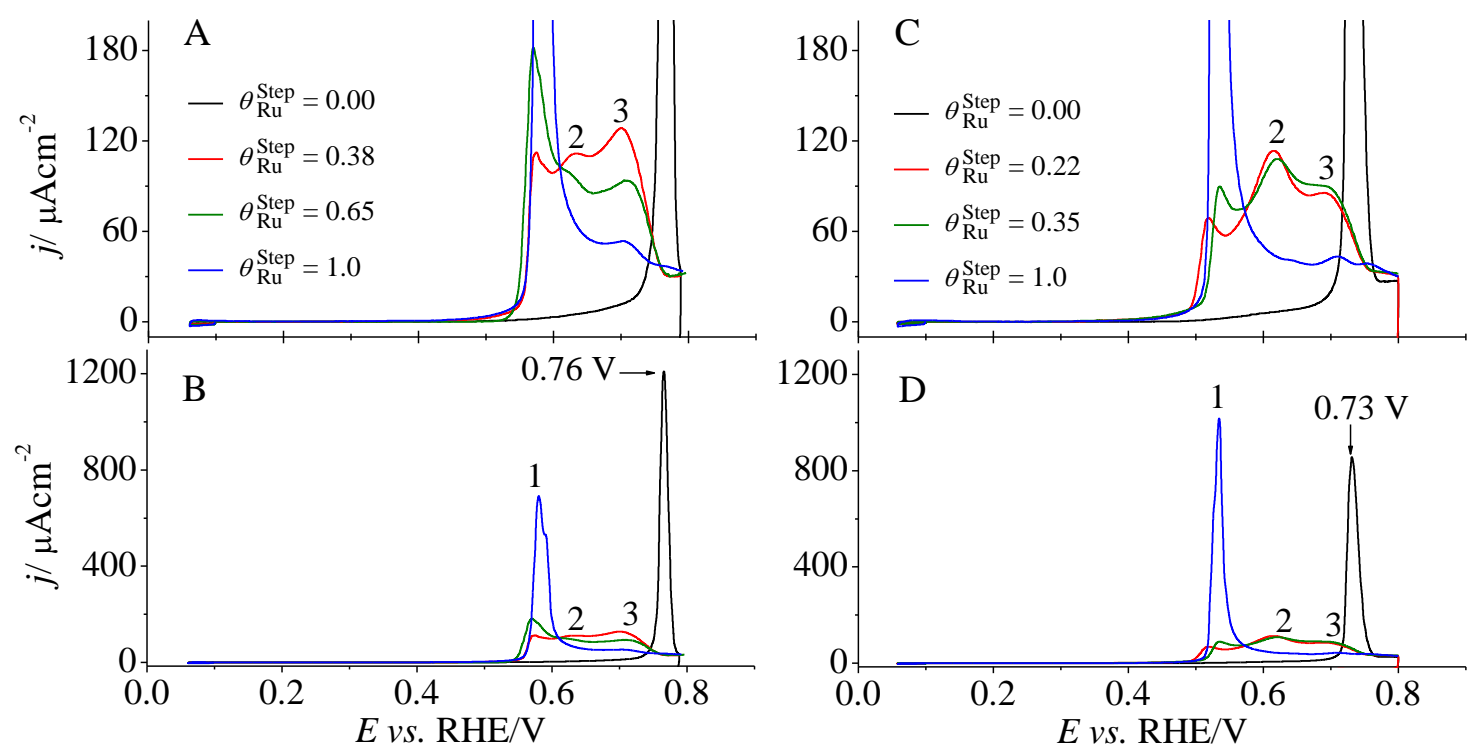

Fig. 2. CO adlayer oxidation on pure and $\mathrm{Ru}$ modified $\mathrm{Pt}(h k l)$ stepped electrodes: A: Pt(554); C: Pt(332). The panels B and D correspond to the panels A and C, respectively, presented on an extended scale. Data recorded at $0.05 \mathrm{~V} \mathrm{~s}^{-1}$ in $0.1 \mathrm{M} \mathrm{HClO}_{4}$. 


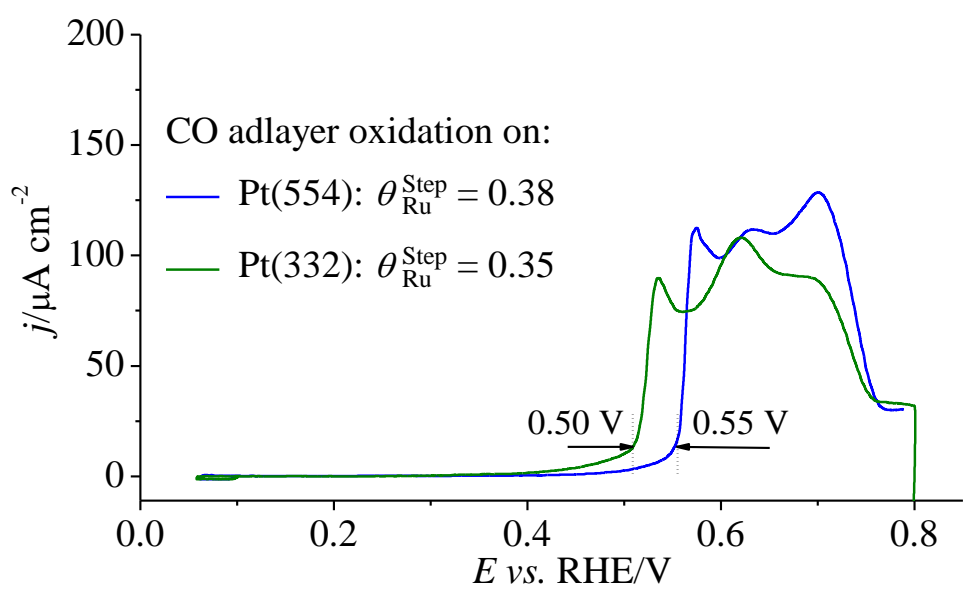

Fig. 3. Comparison between two voltammetric profiles of $\mathrm{CO}$ oxidation on $\operatorname{Pt}(554)$ and $\mathrm{Pt}(332)$ with their steps modified by $\mathrm{Ru}$ at similar coverages. Data recorded in $0.1 \mathrm{M}$ $\mathrm{HClO}_{4}$ at $0.05 \mathrm{~V} \mathrm{~s}^{-1}$. 

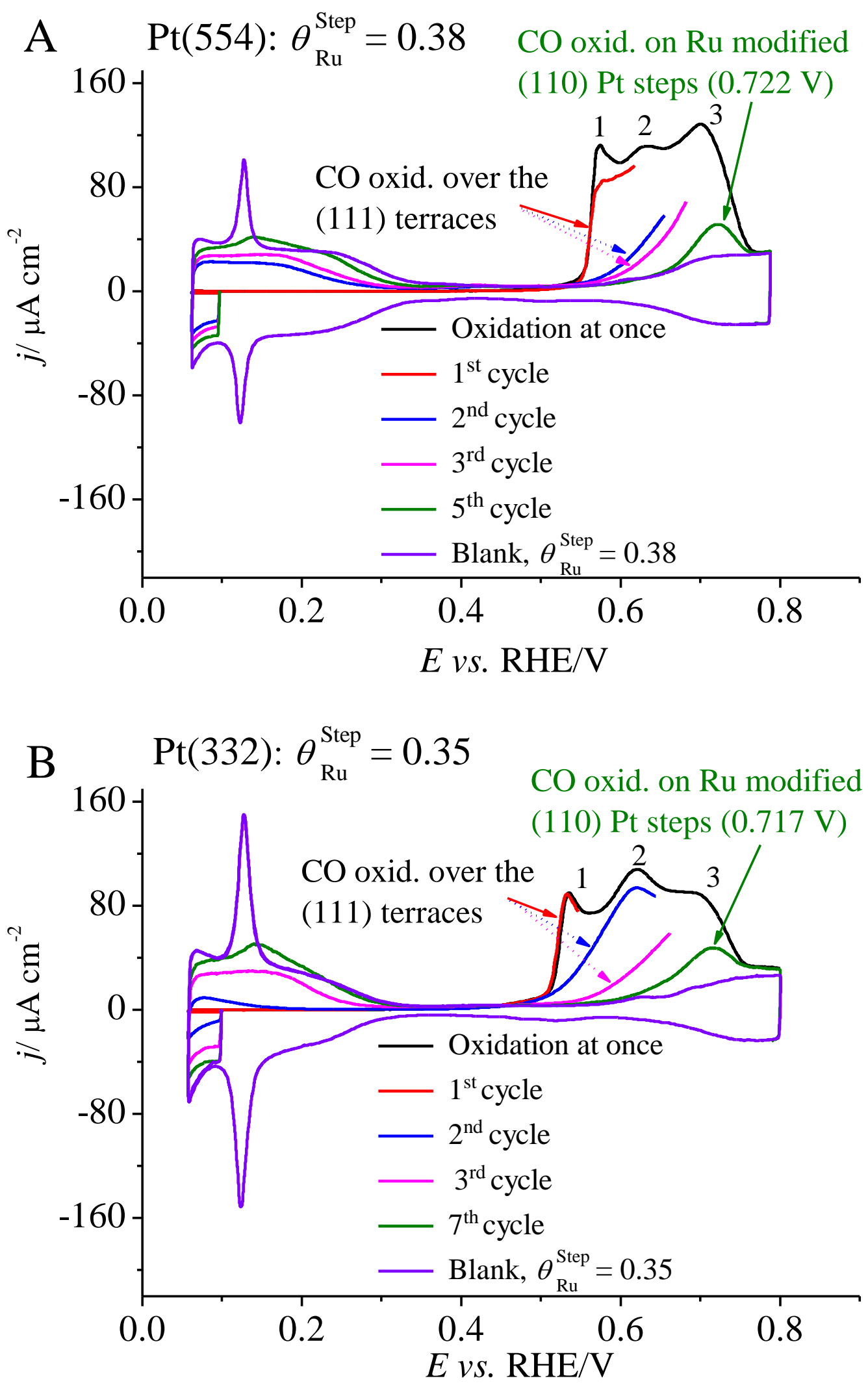

Fig. 4. Successive voltammetric cycles (indicated) collected during the oxidation of a CO adlayer on pure $\operatorname{Pt}(554)$ and $\operatorname{Pt}(332)$ and with their steps modified by $\mathrm{Ru}$. Data consisted in selecting a low upper potential limit to provoke partial $\mathrm{CO}$ oxidations. Data recorded in $0.1 \mathrm{M} \mathrm{HClO}_{4}$ at $0.05 \mathrm{~V} \mathrm{~s}^{-1}$. 


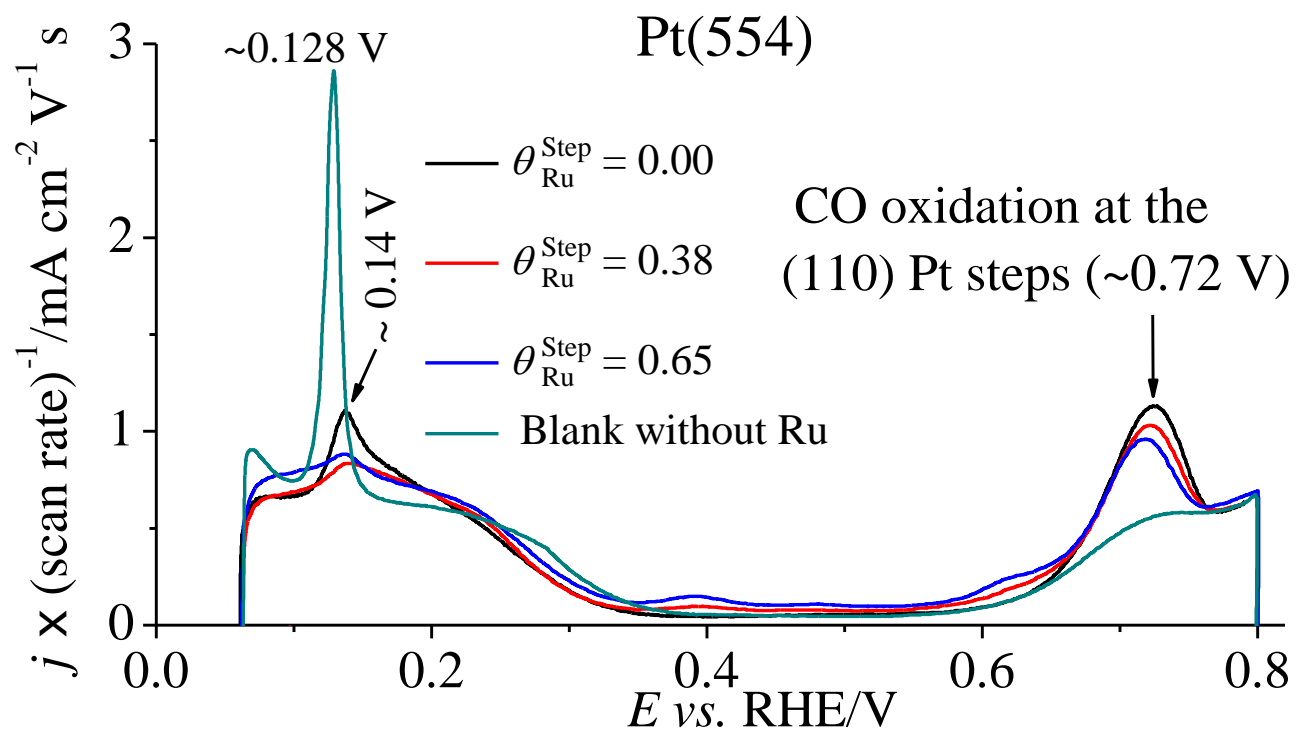

Fig. 5. Voltammetric cycles of $\mathrm{CO}$ oxidation on Ru-modified Pt steps (coverage indicated) and on Pure $\mathrm{Pt}(554)$ in $0.1 \mathrm{M} \mathrm{HClO}_{4}$. Data recorded at $0.05 \mathrm{~V} \mathrm{~s}^{-1}$. 


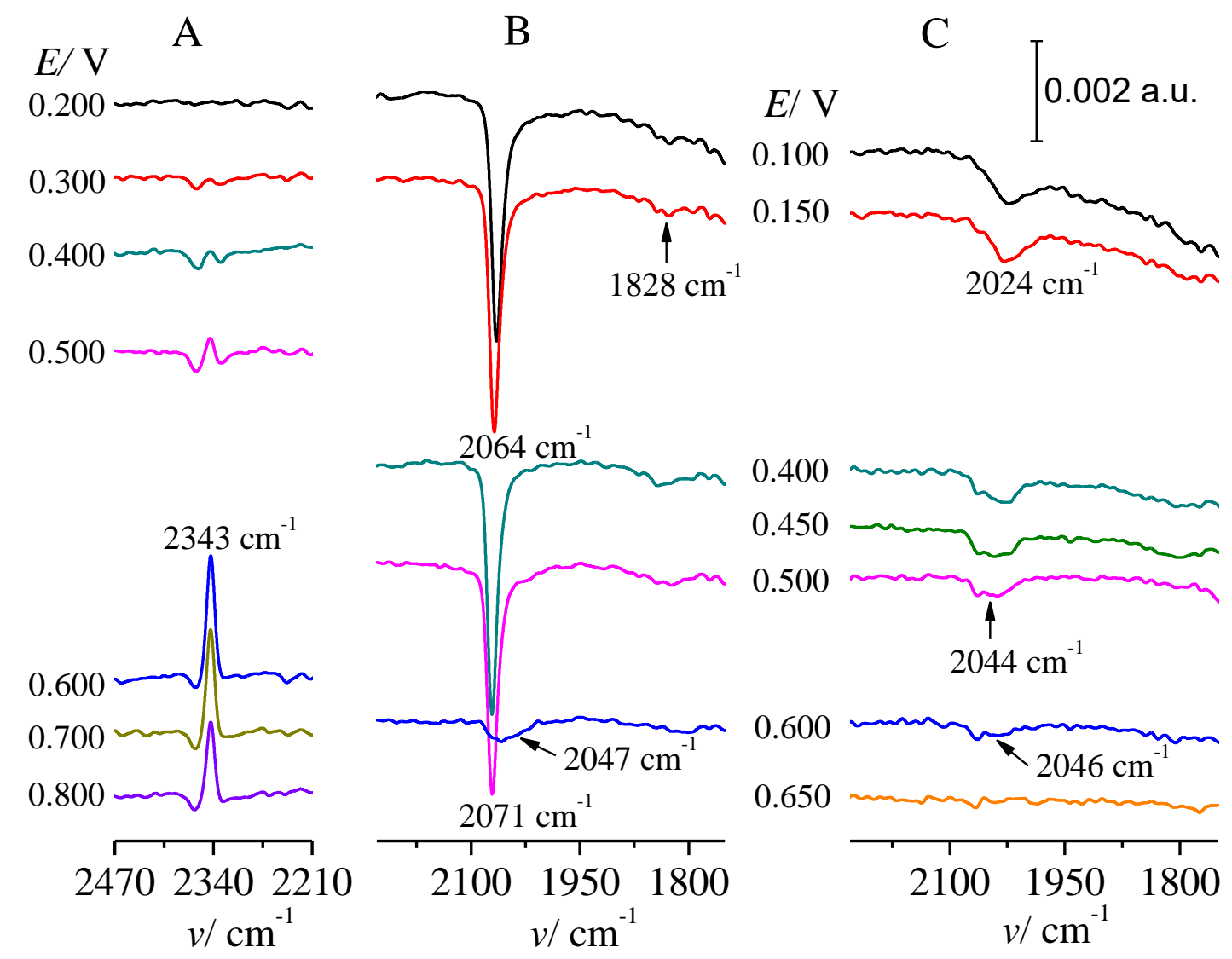

Fig. 6. In situ FTIR spectra of an adsorbed CO adlayer on a pure $\operatorname{Pt}(332)$ electrode. In panel $\mathrm{A}$, the reference was collected at $0.060 \mathrm{~V}$, while for the panels $\mathrm{B}$ and $\mathrm{C}$, the reference spectra were recorded $0.800 \mathrm{~V}$. Some spectra have been omitted for purposes of clarity. Data recorded in $0.1 \mathrm{M} \mathrm{HClO}_{4}$. 


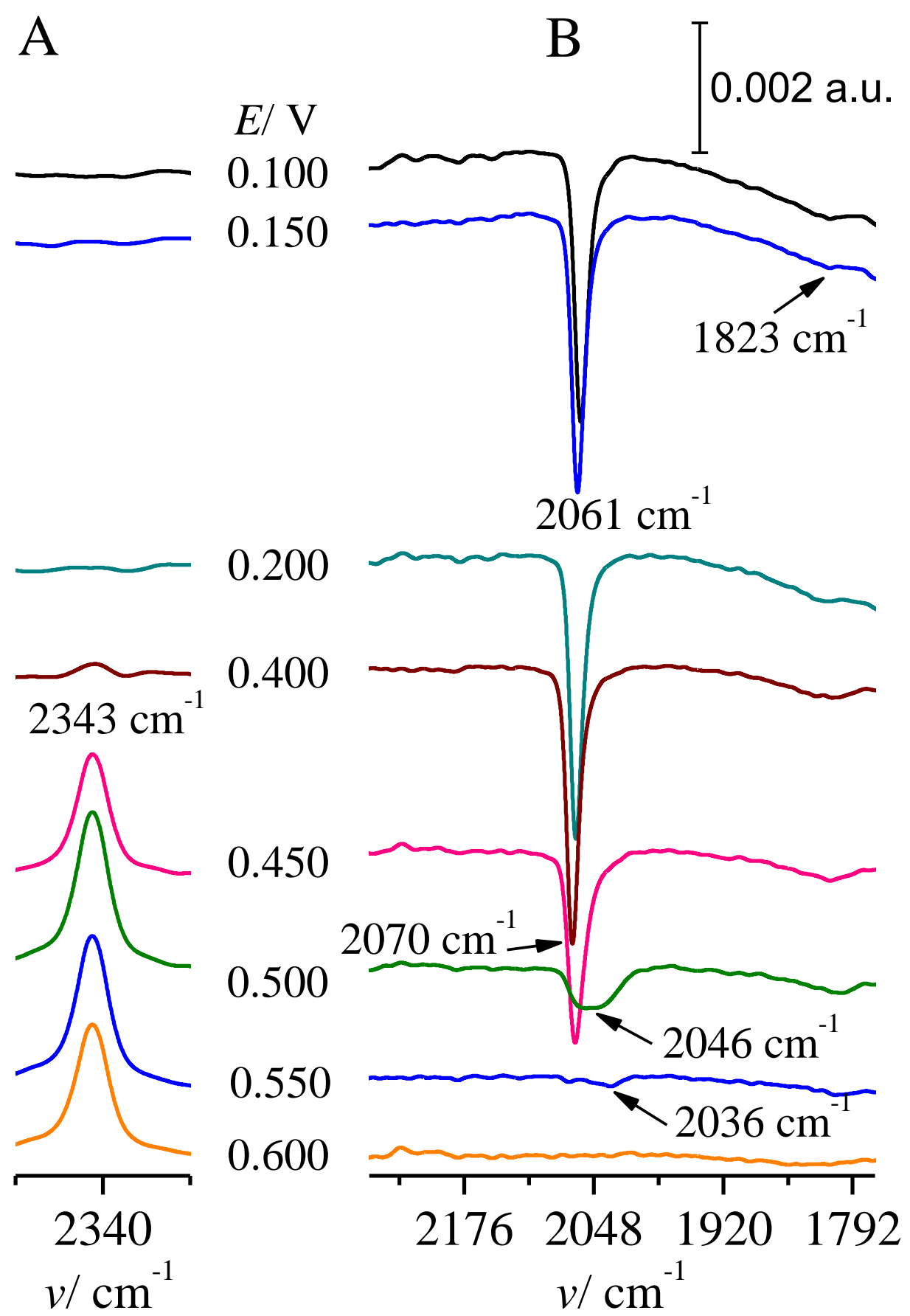

Fig. 7. In situ FTIR spectra of an adsorbed CO adlayer on a Ru modified Pt(332) electrode $\left(\theta_{\mathrm{Ru}}^{\text {Step }} \simeq 0.58\right)$. Some spectra have been omitted for clarity. In panel A, the reference spectrum was taken at $0.060 \mathrm{~V}$, while in $\mathrm{B}$, the reference spectrum was taken in $0.800 \mathrm{~V}$. Data recorded in $0.1 \mathrm{M} \mathrm{HClO}_{4}$. 


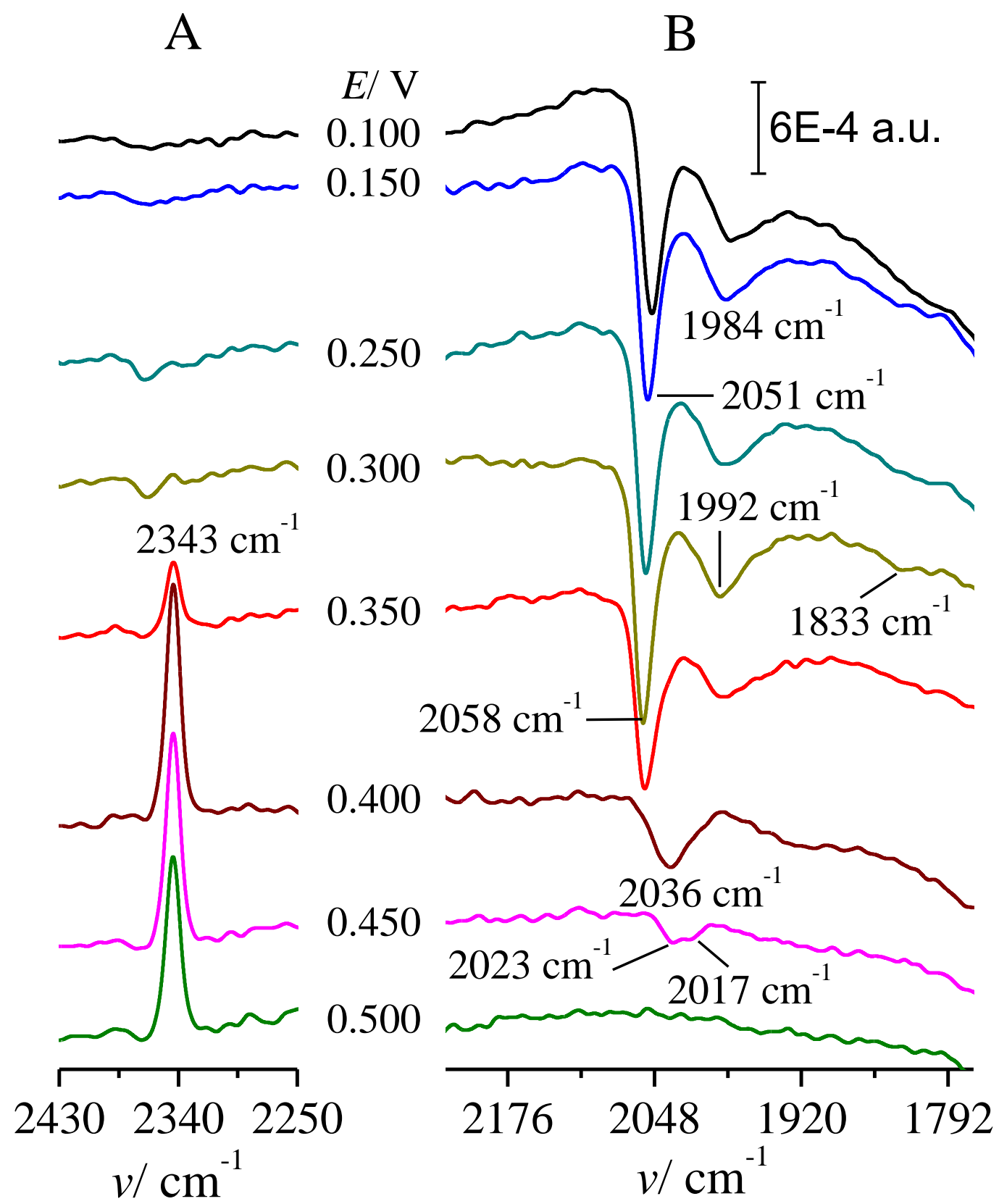

Figure 8. In situ FTIR spectra of an adsorbed CO adlayer on a Ru modified $\operatorname{Pt(332)}$ electrode $\left(\theta_{\mathrm{Ru}}^{\text {Step }}=1.0\right.$ plus $\left.\theta_{\mathrm{Ru}}^{\text {Terrace }} \simeq 0.35\right)$. In panel A, the reference spectrum was taken at $0.060 \mathrm{~V}$, while in $\mathrm{B}$, the reference spectrum was taken in $0.800 \mathrm{~V}$. Data recorded in 0.1 $\mathrm{M} \mathrm{HClO}_{4}$. 


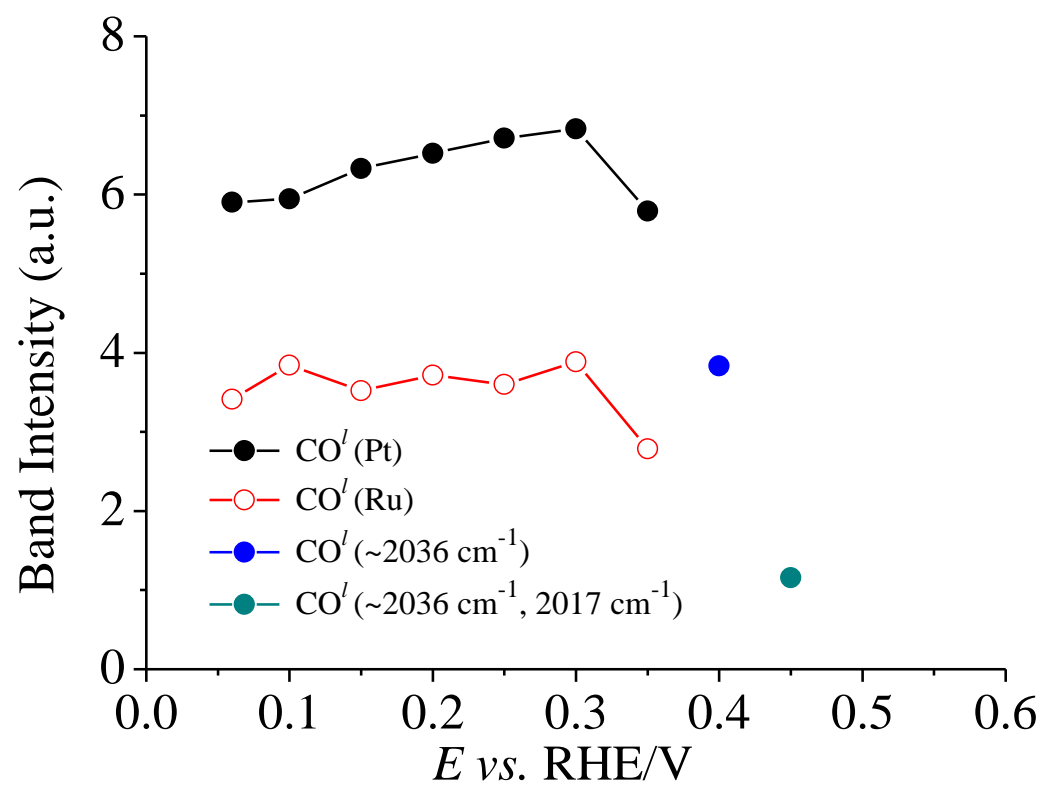

Fig. 9. Integrated band intensities for adsorbed $\mathrm{CO}$ on sites of $\mathrm{Pt}$ and $\mathrm{Ru}$ for a Ru modified $\operatorname{Pt}(332)$ electrode $\left(\theta_{\mathrm{Ru}}^{\text {Step }}=1.0\right.$ plus $\left.\theta_{\mathrm{Ru}}^{\text {Terrace }} \simeq 0.35\right)$. Data extracted from the Figure 8. 


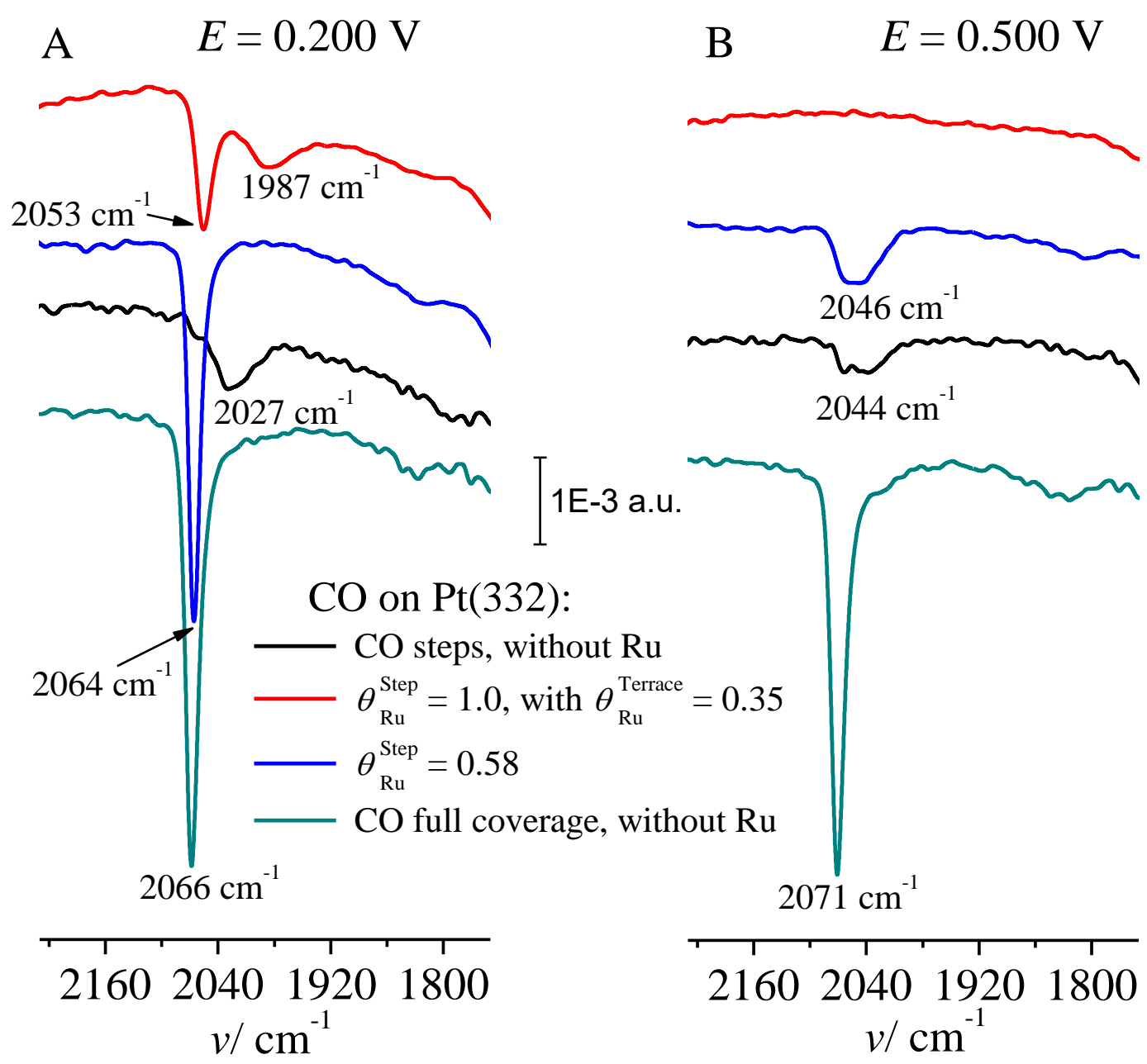

Fig. 10. In situ FTIR spectra of CO on pure and Ru modified $\operatorname{Pt}(332)$ electrode $\left(\theta_{\mathrm{Ru}}^{\text {Step }} \simeq\right.$ $0.58 ; \theta_{\mathrm{Ru}}^{\text {Step }}=1.0$ plus $\left.\theta_{\mathrm{Ru}}^{\text {Terrace }} \simeq 0.35\right)$ at two electrode potentials. Reference collected at $0.800 \mathrm{~V}$. For the spectra in A, the reference spectra were taken at $0.060 \mathrm{~V}$, while in $\mathrm{B}$, the reference spectra were taken at $0.800 \mathrm{~V}$. Data recorded in $0.1 \mathrm{M} \mathrm{HClO}_{4}$. 


\section{Graphical Abstract}

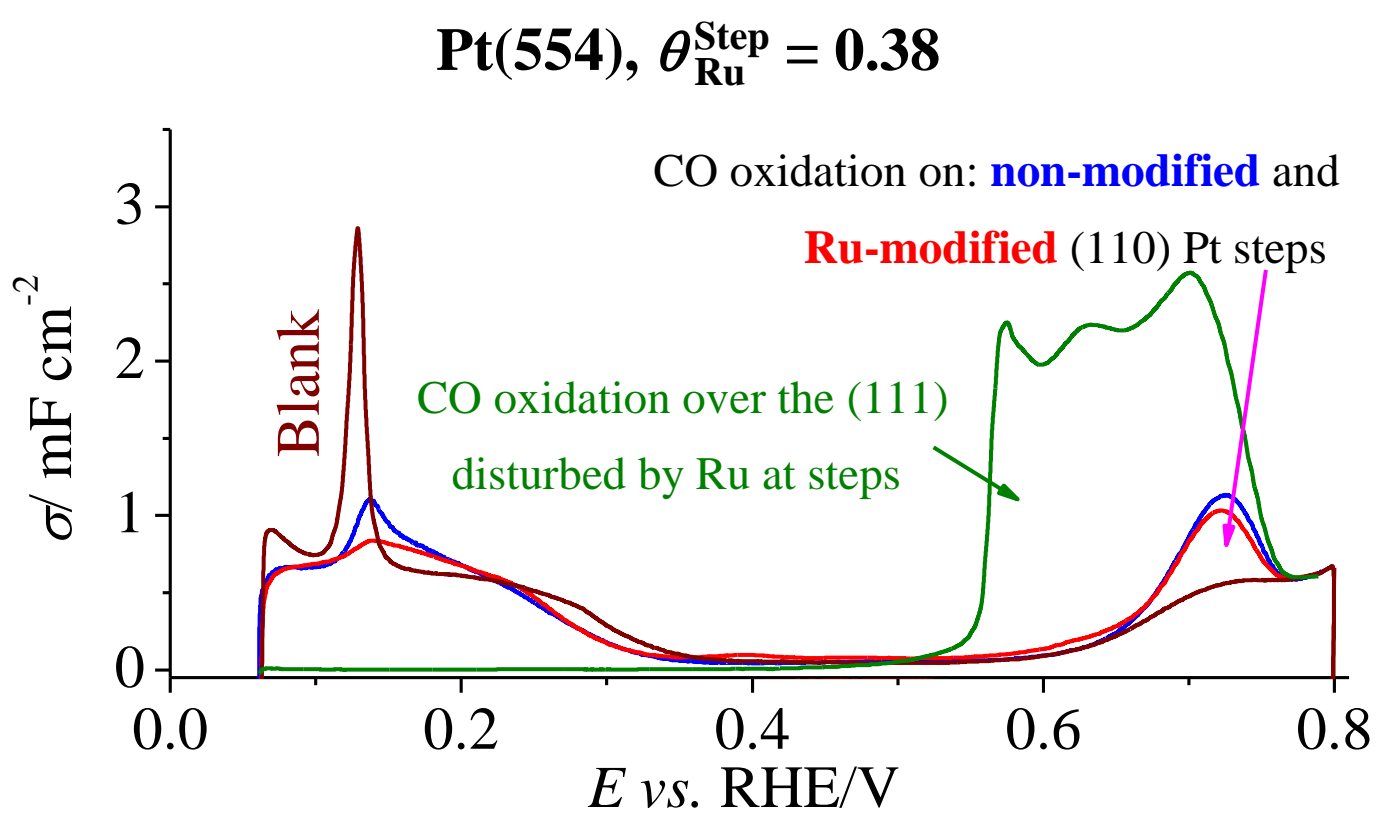

